\title{
Role of the Preoptic Area in Sleep and Thermoregulation
}

\author{
Rebecca Rothhaas and Shinjae Chung* \\ Department of Neuroscience, Perelman School of Medicine, Chronobiology and Sleep Institute, University of Pennsylvania, \\ Philadelphia, PA, United States
}

Sleep and body temperature are tightly interconnected in mammals: warming up our body helps to fall asleep and the body temperature in turn drops while falling asleep. The preoptic area of the hypothalamus (POA) serves as an essential brain region to coordinate sleep and body temperature. Understanding how these two behaviors are controlled within the POA requires the molecular identification of the involved circuits and mapping their local and brain-wide connectivity. Here, we review our current understanding of how sleep and body temperature are regulated with a focus on recently discovered sleep- and thermo-regulatory POA neurons. We further discuss unresolved key questions including the anatomical and functional overlap of sleep- and thermoregulatory neurons, their pathways and the role of various signaling molecules. We suggest that analysis of genetically defined circuits will provide novel insights into the

OPEN ACCESS

Edited by:

Takeshi Sakurai,

University of Tsukuba, Japan

Reviewed by:

Vladyslav Vyazovskiy, University of Oxford, United Kingdom Shaun F. Morrison,

Oregon Health and Science University, United States

*Correspondence: Shinjae Chung shinjaec@pennmedicine.upenn.edu

Specialty section: This article was submitted to Sleep and Circadian Rhythms, a section of the journal

Frontiers in Neuroscience

Received: 06 February 2021 Accepted: 28 May 2021

Published: 01 July 2021

Citation: Rothhaas $R$ and Chung S (2021) Role of the Preoptic Area in Sleep

and Thermoregulation.

Front. Neurosci. 15:664781. doi: 10.3389/fnins.2021.664781 mechanisms underlying the coordinated regulation of sleep and body temperature in health and disease.

Keywords: sleep, thermoregulation, body temperature, preoptic area of the hypothalamus, neural circuits

\section{INTRODUCTION}

In homeothermic animals, sleep, and body temperature are tightly interconnected. The ambient and body temperature influence the amount of sleep. Warming up the body such as taking a warm bath or passive heating promotes sleep (Horne and Staff, 1983; Horne and Shackell, 1987; Bunnell et al., 1988; Morairty et al., 1993; Kräuchi et al., 1999). Animals show preparatory behaviors before sleep such as nest building, social huddling, seeking warm places and curling up to reduce body heat loss (Gordon et al., 2014; Harding et al., 2018; Peever, 2018). Human studies showed that core body temperature starts to decrease a few hours before the sleep onset (Campbell and Broughton, 1994; Landolt et al., 1995; Krauchi and Deboer, 2010). The brain and core temperature in rats also start to decrease before sleep onset, a phenomenon observed for different ambient temperatures (ranging from $10^{\circ} \mathrm{C}$ to $24.6^{\circ} \mathrm{C}$ ) (Alföldi et al., 1990; Franken et al., 1992a,b; Campbell and Broughton, 1994; Landolt et al., 1995). During non-rapid eye movement (NREM) sleep, the brain, and core temperature then decrease with similar magnitudes irrespective of the ambient temperature. In contrast, the tail temperature significantly rises at the NREM sleep onset (at 10 and $21^{\circ} \mathrm{C}$ ) indicating increased vasodilation. NREM sleep is a state with a low level of energy metabolism, cardiovascular, and thermoregulatory functions to conserve energy while feeding is reduced. Central autonomic nervous system activity regulating cardiovascular function and breathing as well as endocrine function is set to support this need during NREM sleep. Energy conservation and cooling of the body and brain are thought to be major functions of the tight interconnection of sleep and thermoregulation (Berger, 1984; McGinty and Szymusiak, 1990; Heller and Ruby, 2004). 
The preoptic area of the hypothalamus (POA), located in the anterior part of the hypothalamus, is known to be critical for both thermoregulation and sleep. In addition, it is also involved in regulating energy homeostasis, parenting, and sexual behaviors, each of which is controlled by dedicated circuits (Simerly, 2002; Dulac et al., 2014; McKinley et al., 2015; Kohl and Dulac, 2018; Yu et al., 2018; Tsukahara and Morishita, 2020). However, how these circuits are interconnected within the POA and beyond to coordinate these complex behaviors is still not very well understood.

The recent development of neuroscience tools for circuit analysis has significantly helped to identify the specific cell types and regions within the POA that are crucial for sleep and body temperature regulation (Figure 1). We will review our current knowledge on the neural mechanisms underlying sleep and thermoregulation. Finally, we will discuss key questions that remain unresolved to elucidate how sleep and body temperature are coordinated within the POA.

\section{ROLE OF THE POA IN SLEEP REGULATION}

In the 1920s, lesions in the POA were found to be associated with insomnia in human patients affected by encephalitis lethargica (von Economo, 1930). In rats, various brain regions were systemically lesioned, and the POA was confirmed to be a critical sleep center (Nauta, 1946). This finding was also reproduced in cats showing that the size and location of the lesions within the POA are correlated with the severity of sleeplessness (McGinty and Sterman, 1968). Conversely, electrically stimulating the POA in cats promotes sleep (Sterman and Clemente, 1962b; Figure 1A). Furthermore, insomnia induced by POA lesions after injection of the neurotoxin ibotenic acid (Sallanon et al., 1989; Lu et al., 2000; Figure 1B) was reversed by injection of muscimol into the ventrolateral part of the posterior hypothalamus (Sallanon et al., 1989) suggesting that the sleep-promoting effect of POA neurons is mediated by their inhibitory projections to the posterior hypothalamus. c-Fos immunohistochemistry revealed the existence of sleep-active neurons in the POA (Sherin et al., 1996; Gong et al., 2004; Gvilia et al., 2006; Chung et al., 2017; Figure 1C). In sleeping rats, the number of c-Fos labeled neurons is elevated in the ventrolateral preoptic area (VLPO) and median preoptic nucleus (MnPO) and is correlated with the amount of sleep before sacrificing the animal (Sherin et al., 1996; Gong et al., 2004). Electrophysiological recordings in the POA of rats and mice further demonstrated in vivo the existence of neurons that are active during rapid eye movement (REM) and/or NREM sleep (Koyama and Hayaishi, 1994; Osaka and Matsumura, 1994; Szymusiak et al., 1998; Takahashi et al., 2009). The firing rate of VLPO neurons was elevated during the homeostatic sleep rebound following deprivation, but remained at low levels throughout the deprivation period (Szymusiak et al., 1998). Similarly, c-Fos levels in VLPO neurons were not elevated, if rats were sacrificed right after sleep deprivation (Sherin et al., 1996). These results suggest that the activity of VLPO neurons reflects the amount or intensity of sleep, rather than the sleep propensity accumulated during wakefulness. TetTagging was applied to express the excitatory hM3DGq receptor in c-Fos activated neurons followed by a deprivationinduced sleep rebound (Zhang et al., 2015). Chemogenetically reactivating these neurons enhanced sleep confirming their causal role in promoting sleep. This study further suggests that sleep-promoting neurons are located throughout a broader area within the POA than previously thought.

c-Fos immunohistochemistry also provided evidence for a role of the POA in REM sleep regulation. c-Fos expression was examined in the VLPO and MnPO during spontaneous sleep, REM sleep restriction and subsequent REM sleep recovery (Gvilia et al., 2006). The number of c-Fos neurons was highest in the REM sleep restriction group suggesting that they are involved in the homeostatic regulation of REM sleep. Furthermore, when REM sleep was enriched after periods of dark exposure, the number of c-Fos-expressing cells in the extended VLPO (the area medially and dorsally extending from the VLPO) was correlated with the amount of REM sleep and its lesion decreased REM sleep (Lu et al., 2002).

\section{Molecular and Circuit Level Characterization of POA Sleep Neurons}

A high percentage of sleep-active neurons identified using c-Fos immunohistochemistry has been shown to express galanin in multiple mammalian species including rats, mice, degus, and cats (Sherin et al., 1998; Gaus et al., 2002). In rats, galanin labels a pure population of c-Fos-labeled sleep neurons in the VLPO, whereas in mice about $33 \%$ of c-Fos-labeled wake-active neurons also contain galanin (Gaus et al., 2002), indicating that this neuropeptide labels diverse neural populations in mice. Optogenetic stimulation of galanin neurons promotes wakefulness (Chung et al., 2017) or NREM sleep (Kroeger et al., 2018) depending on the stimulation frequency. Chemogenetic stimulation of galanin neurons promoted sleep (Kroeger et al., 2018). Surprisingly, chronic ablation of these neurons through cell type specific expression of the apoptotic Caspase 3 increased the amount of NREM sleep, while reducing wakefulness ( $\mathrm{Ma}$ et al., 2019). The duration of NREM sleep and wake bouts was significantly decreased, suggesting that sleep is highly fragmented in the absence of galanin neurons. Ablating galanin neurons also impaired sleep homeostasis: mice slept less and exhibited a reduced increase in delta power during NREM sleep following sleep deprivation. Using fiber photometry, a recent study recorded the calcium activity of the galanin population in the POA and found that they are most active during REM sleep [published in preprint form Miracca et al. (2020)]. Future studies to measure the activity of galanin neurons at the single cell level will further clarify their role in sleep control.

A recent study used cell type and projection specific targeting and gene profiling to identify molecular markers that are enriched in the POA neurons that promote sleep and are sleepactive (Chung et al., 2017). Such sleep neurons are thought to promote sleep by suppressing arousal systems in downstream areas including the tuberomammillary nucleus (TMN), raphe nucleus, and locus coeruleus (LC) (Saper and Fuller, 2017; 


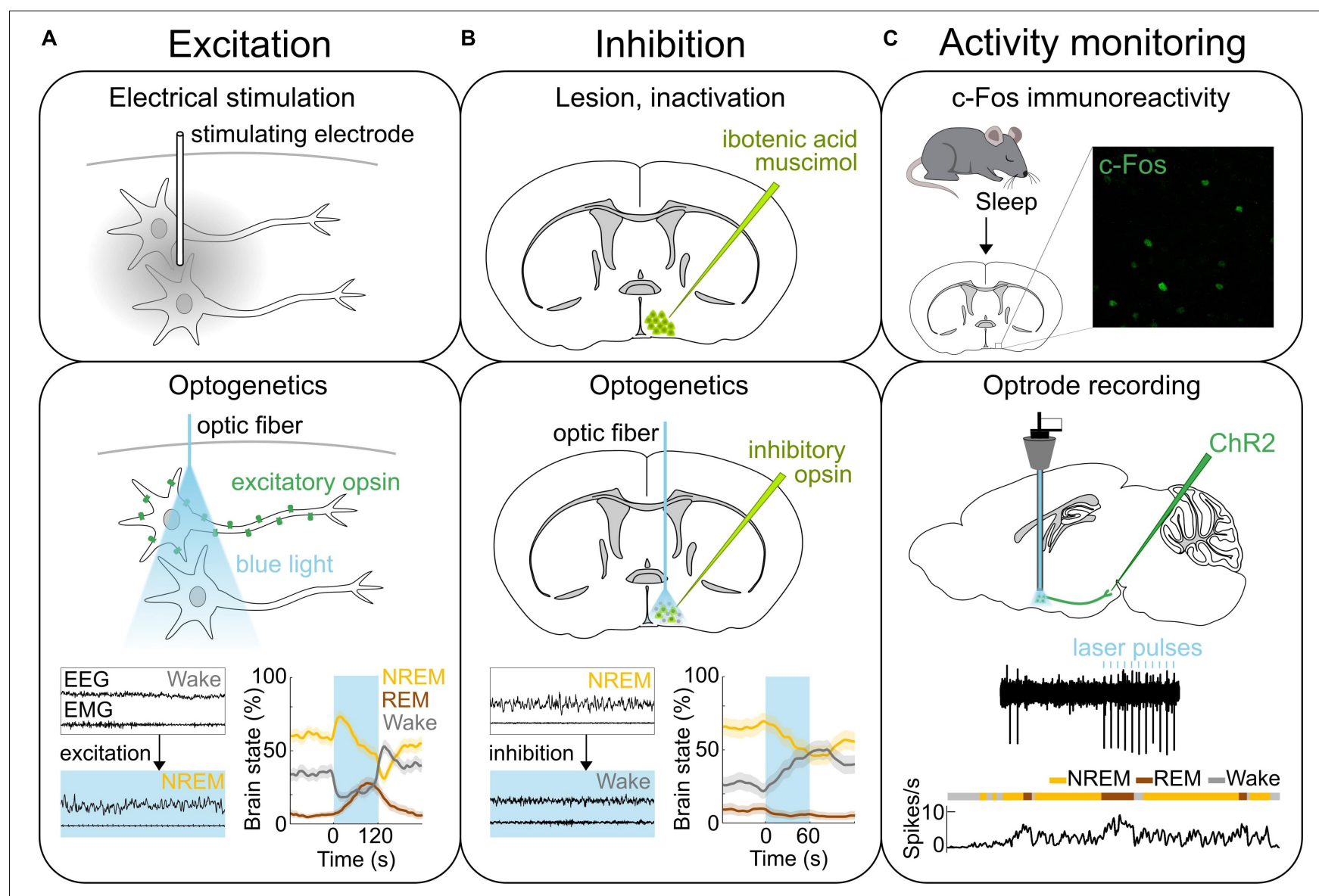

FIGURE 1 | Methods of neural activity manipulation and monitoring. (A) Methods for activating neurons. Top, Electrical stimulation allows for activating neurons in the area where the stimulating electrode is located. Middle, Expressing light-activated excitatory opsins such as channelrhodopsin-2 (ChR2) in genetically-defined neurons allows for the manipulation of specific neural populations on the order of milliseconds using light (Deisseroth, 2015; Grosenick et al., 2015; Deisseroth and Hegemann, 2017; Kim et al., 2017). Bottom, Optogenetic stimulation of ChR2 expressing GABAPOA $\rightarrow$ TMN neurons promotes sleep. Bottom left, Example EEG and EMG traces before and during laser stimulation (blue shading). Bottom right, Percentage of time in NREM, REM or wake state before, during, and after laser stimulation (blue shading). (B) Methods for inactivating neural activity. Top, The specific brain region can be lesioned or inactivated for example by injecting the neurotoxin ibotenic acid or muscimol. Middle, Expression of light sensitive inhibitory opsins in genetically-defined neurons enables the inhibition of specific neural populations (Wiegert et al., 2017). Bottom, Optogenetic inhibition of the $\mathrm{iC}++$ expressing GABA ${ }^{P O A} \rightarrow T M N$ neurons suppresses sleep. Left, Example EEG and EMG traces before and during laser stimulation (blue shading). Right, Percentage of time in NREM, REM or wake state before, during, and after laser stimulation (blue shading). (C) Methods for recording neural activity. Top, c-Fos immunohistochemistry has been used to detect neurons in the POA that are activated following sleep. Example POA neurons stained for expression of c-Fos (green) following deprivation-induced sleep rebound. Middle and bottom, Optrodes allow for identifying ChR2-expressing neurons and recording their spiking activity during sleep and wakefulness. An example recording from GABA ${ }^{\mathrm{POA} \rightarrow T M N}$ neurons. Reproduced from Chung et al. (2017). Sagittal and coronal brain scheme adapted from Allen Mouse Brain Atlas (@Allen Brain Atlas APl. Available from http://api.brain-map.org).

Scammell et al., 2017). Sleep-activated c-Fos neurons project to the TMN, a brain region containing wake-active histamine neurons (Sherin et al., 1996; Chung et al., 2017; Figure 2). Monosynaptic rabies tracing revealed that POA neurons that directly innervate histamine neurons in the TMN are largely GABAergic ( $\gamma$-aminobutyric-acid-releasing) and express c-Fos in response to sleep (Chung et al., 2017; Saito et al., 2018). GABA release in the posterior hypothalamus of cats increases during NREM sleep compared to wakefulness, likely to facilitate NREM sleep and one of the potential sources of GABA could be the POA (Nitz and Siegel, 1996). To investigate the causal role of POA GABAergic neurons projecting to the TMN $\left(\mathrm{GABA}^{\mathrm{POA} \rightarrow \mathrm{TMN}}\right)$ in sleep control, a retrograde lentivirus with Cre-dependent expression of channelrhodopsin-2 (ChR2) was injected into the TMN (Chung et al., 2017). Optogenetic activation of the $\mathrm{GABA}^{\mathrm{POA} \rightarrow \mathrm{TMN}}$ neurons significantly promoted NREM and REM sleep, while optogenetic inhibition suppressed sleep, demonstrating their sufficient and necessary role in sleep regulation (Figures 1A,B). Optrode recordings allow for the identification of ChR2-expressing neurons to monitor their activity during sleep and wakefulness (Figure 1C). The firing rate of ChR2-tagged GABA ${ }^{\mathrm{POA}} \rightarrow \mathrm{TMN}$ neurons was higher during REM and NREM sleep than during wakefulness. Furthermore, gene profiling revealed a variety of molecular markers for the $\mathrm{GABA}^{\mathrm{POA} \rightarrow \mathrm{TMN}}$ neurons. In particular, cholecystokinin (CCK), corticotropin-releasing hormone (CRH), and tachykinin 1 (TAC1) are highly enriched in $\mathrm{GABA}^{\mathrm{POA} \rightarrow \mathrm{TMN}}$ neurons, and optogenetic and chemogenetic manipulation demonstrated 


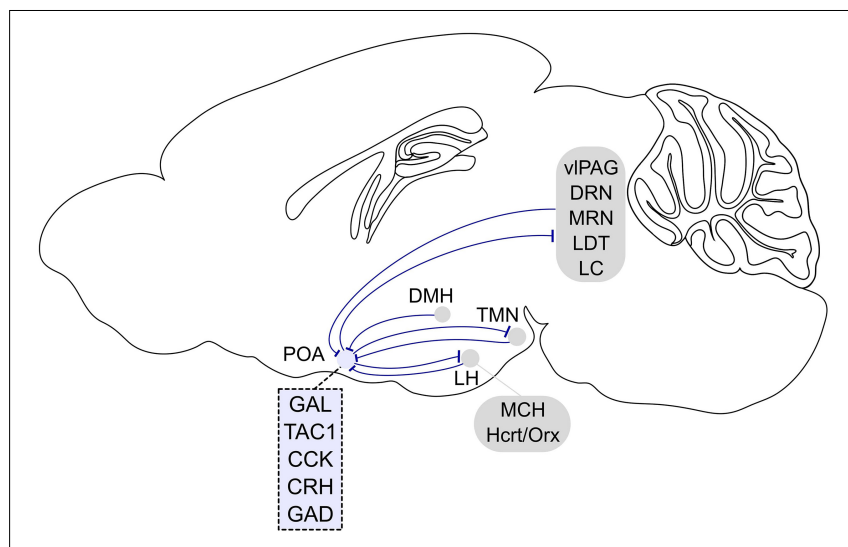

FIGURE 2 | Afferent and efferent projections of sleep regulatory POA neurons. Sleep promoting GABAergic POA neurons inhibit histamine neurons in the tuberomammillary nucleus (TMN). In turn, histaminergic TMN neurons project to the POA, and histamine indirectly inhibits putative VLPO sleep neurons. POA GABAergic neurons also densely project to the lateral hypothalamus $(\mathrm{LH})$ and directly inhibit hypocretin/orexin (Hcrt/Orx) neurons. The POA in turn receives inputs from the $\mathrm{LH}$, and a small fraction of neurons contain melanin-concentrating hormone $(\mathrm{MCH})$ or Hcrt/Orx. GABAergic neurons in the $\mathrm{LH}$ also directly innervate POA galanin neurons. The POA receives inputs from dorsomedial hypothalamus $(\mathrm{DMH})$ galanin neurons that are NREM promoting and REM suppressing. POA neurons project to brainstem regions such as the ventrolateral periaqueductal gray (vIPAG), raphe nuclei (DRN, MRN), laterodorsal tegmental nucleus (LDT), and locus coeruleus (LC). In turn, the $\mathrm{POA}$ receives inputs from these brain stem regions. Molecular markers labeling sleep regulatory POA neurons are galanin (GAL), tachykinin 1 (TAC1), cholecystokinin (CCK), and corticotropin-releasing hormone $(\mathrm{CRH})$. Most sleep neurons are GABAergic and express GAD (glutamic acid decarboxylase). Sagittal brain scheme adapted from Allen Mouse Brain Atlas (CAllen Brain Atlas API. Available from http://api.brain-map.org).

that these subpopulations of POA neurons are indeed sleeppromoting and necessary for sleep.

Using single-cell RNA sequencing (scRNA-seq) together with multiplexed error robust fluorescence in situ hybridization (MERFISH), a recent study revealed that the POA contains a multitude of different cell populations (Moffitt et al., 2018). This approach revealed seven clusters that are enriched in galanin expression, and each cluster was characterized by the expression of distinct marker genes such as peptides, sex steroid, and neuropeptide receptors. About $70 \%$ of galanin neurons are GABAergic and a subclass of the inhibitory neurons expresses tyrosine hydroxylase, a marker for neurons involved in maternal care and oxytocin secretion and are located in the sexually dimorphic anteroventral periventricular nucleus (AVPe) in the POA (Scott et al., 2015; Moffitt et al., 2018). This study revealed a staggering heterogeneity of neurons within the POA that awaits to be further characterized using recently developed tools to fully understand how different POA subpopulations generate and coordinate different behaviors.

\section{Output and Input Pathways of POA Sleep Neurons}

Preoptic area of the hypothalamus neurons project to multiple brain regions that are involved in various behaviors
(Steininger et al., 2001). In addition to the TMN discussed above, both anterograde and retrograde tracing have shown that POA neurons project to brainstem regions such as the laterodorsal tegmental nucleus (LDT), dorsal raphe (DRN) and median raphe nucleus (MRN), LC, and ventrolateral periaqueductal gray (vlPAG) (Steininger et al., 2001; Lu et al., 2002; Hsieh et al., 2011; Saito et al., 2013; Figure 2). Retrograde tracing from these regions together with c-Fos immunohistochemistry after periods of dark exposure to enhance REM sleep showed retrogradely labeled c-Fos cells in the extended VLPO (Lu et al., 2002), suggesting that POA neurons projecting to LDT, DRN, and LC are involved in REM sleep regulation. Serotonergic DRN and noradrenergic LC cells are silent during REM sleep (Aston-Jones and Bloom, 1981; Heym et al., 1982; Thakkar et al., 1998). The suppression of the DRN and LC during REM sleep is likely caused by GABA release, and one of the potential sources providing GABAergic inputs to these areas is the POA (Luppi et al., 1995; Nitz and Siegel, 1997; Gervasoni et al., 2000; Lu et al., 2002). Increasing the activity of POA neurons through local warming inhibited the DRN cells, providing further evidence for their inhibition by POA neurons (Guzmán-Marín et al., 2000). Thus, these studies suggest that increased activity of POA GABAergic neurons contributes to the suppression of DRN and LC neurons during REM sleep.

Preoptic area of the hypothalamus GABAergic neurons also densely project to the lateral hypothalamus ( $\mathrm{LH})$, and monosynaptically restricted rabies tracing confirmed that they innervate hypocretin/orexin (Hcrt/Orx) neurons in the LH (Saito et al., 2013, 2018). Furthermore, whole cell patch clamp recordings of Hcrt/Orx neurons while optogenetically stimulating POA GABAergic axons in the $\mathrm{LH}$ showed that the POA axons inhibit Hcrt/Orx neurons through $\mathrm{GABA}_{\mathrm{A}}$ receptormediated synaptic transmission (Saito et al., 2013).

To identify inputs to the VLPO, the retrograde tracer cholera toxin B (CTB) was injected into the VLPO and CTB-labeled neurons were examined throughout the whole brain (Chou et al., 2002). CTB containing neurons were found in multiple brain regions such as the $\mathrm{TMN}$, raphe nuclei, ventrolateral medulla, and LC (Figure 2). Immunohistochemistry confirmed that histaminergic, noradrenergic, and serotonergic fibers densely innervate the POA (Chou et al., 2002) suggesting that monoaminergic nuclei are reciprocally connected with the POA. In addition, the VLPO receives inputs from various hypothalamic regions such as the $\mathrm{MnPO}, \mathrm{LH}$, and dorsomedial hypothalamus (DMH). VLPO sleep neurons are thus likely influenced by a variety of brain regions regulating different behaviors and functions.

The impact of monoamines on the activity of putative sleep neurons in the POA was studied in vitro using slice physiology. Putative sleep neurons were identified by the presence of lowthreshold spikes (LTSs) (Gallopin et al., 2000). Two-thirds of neurons in the VLPO are LTS cells, which matches the proportion of sleep-active neurons in vivo. LTS cells are GABAergic and are inhibited by wake-promoting substances such as noradrenaline (NA) and acetylcholine. Some of the LTS cells are either excited or inhibited by serotonin (5-HT), but not histamine (Gallopin et al., 2000, 2005). A recent study using rabiesmediated monosynaptic retrograde tracing showed that POA 
neurons innervating histaminergic neurons in the TMN and Hcrt/Orx expressing neurons in the LH were potently inhibited by NA and 5-HT (Saito et al., 2018). Thus, putative POA sleep neurons, either defined by the presence of LTS spikes or their connectivity with the TMN histaminergic neurons or LH Hcrt/Orx neurons, receive monoaminergic innervation. Consistent with these findings, electrical stimulation of the LC inhibited the activity in $50 \%$ of sleep-active neurons through $\alpha_{2}$-adrenoreceptors (Osaka and Matsumura, 1994, 1995). The inhibited sleep-active neurons were either most active during NREM sleep or during both NREM and REM sleep compared to wakefulness. In contrast, the activity in $47 \%$ of wakeactive neurons was increased by LC stimulation. These results suggest that sleep and wake-active neurons in the POA receive inhibitory and excitatory inputs from the LC, respectively. Given that electrical stimulation may stimulate different cell types within and surrounding the LC including GABAergic neurons, which have also been implicated in arousal (BretonProvencher and Sur, 2019), it is important to disentangle the roles of NA- or GABAergic neurons on the brain state through their effects on the POA. Therefore, these results suggest that sleep neurons are inhibited by wake-promoting transmitters such as noradrenaline and acetylcholine, and the reciprocal inhibitory interactions between sleep neurons in the POA and arousal systems may be a key circuit motif underlying the regulation of sleep-wake states (Saper and Fuller, 2017; Scammell et al., 2017).

The POA also receives major inputs from various hypothalamic regions (Figure 2). Histamine neurons in the TMN project to the POA, and histamine indirectly inhibits LTStype VLPO neurons through local interneurons (Williams et al., 2014). The POA also receives inputs from neurons in the $\mathrm{LH}$; a small fraction of those is positive for melanin-concentrating hormone $(\mathrm{MCH})$ or Hcrt/Orx (21 and 4\%, respectively) (Chou et al., 2002). GABAergic neurons in the LH are wake- and REM sleep-active as shown using fiber photometry and directly innervate VLPO neurons that were identified by galanin expression and an inhibitory response to NA (Venner et al., 2019). The DMH has also been shown to innervate the POA (Chou et al., 2002; Chen et al., 2018). In particular, galanin labels a subpopulation of GABAergic neurons in the $\mathrm{DMH}$ projecting to the POA (Chen et al., 2018). Optogenetic stimulation of POA-projecting DMH galanin neurons suppressed REM sleep and promoted NREM sleep. Microendoscopy calcium imaging of the POA-projecting galanin neurons in the $\mathrm{DMH}$ revealed that their activity is low during REM sleep, and high during NREM sleep. In future studies, it would be of great interest to elucidate which specific POA subregions and cell types the DMH galanin neurons innervate to better understand how the $\mathrm{DMH}$, another key brain region for thermoregulation, interacts with the POA.

\section{Impact of Somnogens on POA Sleep Neurons}

Ishimori (1909) and Legendre and Piéron (1913) discovered that injecting cerebrospinal fluid from a sleep-deprived dog into a normal dog promotes sleep. These studies suggest that prolonged wakefulness leads to the accumulation of sleep-promoting substances, termed somnogens.

Adenosine has been extensively studied as an endogenous somnogen. The adenosine level increases with prolonged wakefulness and decreases throughout sleep (Porkka-Heiskanen et al., 1997). During sleep deprivation, adenosine strongly increases in the basal forebrain and to a lesser extent in the cortex, but not in the other regions that were examined (PorkkaHeiskanen et al., 2000). The site-specific increase of adenosine during sleep deprivation suggests that its sleep-promoting effect is primarily mediated through signaling in the basal forebrain. Adenosine regulates neural activity via two receptors: the inhibitory A1 receptors are widely distributed in the brain while the excitatory A2a receptors are mainly located in the striatum, nucleus accumbens, and olfactory bulb (Porkka-Heiskanen and Kalinchuk, 2011). The impact of adenosine on sleep-active POA neurons was also investigated: Injection of an A2a receptor agonist into the lateral ventricle or subarachnoid space promotes sleep and increases c-Fos expression in GABAergic neurons of the MnPO and VLPO (Scammell et al., 2001; Kumar et al., 2013). Systematic injection of an A2a receptor antagonist instead suppressed sleep deprivation induced expression of c-Fos in MnPO and VLPO neurons (Kumar et al., 2013) and attenuated the activity of the sleep-active neurons during sleep deprivation in vivo (Alam et al., 2014).

Prostaglandin $\mathrm{D}_{2} \quad\left(\mathrm{PGD}_{2}\right)$ is another powerful sleeppromoting substance. $\mathrm{PGD}_{2}$ injection into the subarachnoid space promotes NREM sleep, and injecting it just anterior and ventral to the VLPO induces its largest sleep promoting effect (Matsumura et al., 1994). The sleep promoting effect of $\mathrm{PGD}_{2}$ is likely mediated by the leptomeninges, the only area where $\mathrm{PGD}_{2}$ receptors are expressed (Urade et al., 1993; Gerashchenko et al., 1998), and the receptor level is highest in the leptomeninges near the VLPO and TMN (Mizoguchi et al., 2001). PGD $_{2}$ injection increased c-Fos expression in the VLPO and this increase was positively correlated with the amount of sleep, indicating that its sleep promoting effect is through leptomeningeal $\mathrm{PGD}_{2}$ receptors and subsequent activation of VLPO neurons (Scammell et al., 1998). $\mathrm{PGD}_{2}$ infusion to the subarachnoid space near the VLPO/basal forebrain also increased the adenosine level in WT mice, but not in $\mathrm{PGD}_{2}$ receptor-deficient mice (Mizoguchi et al., 2001). $\mathrm{PGD}_{2}$-induced sleep is reduced by an A2a receptor antagonist suggesting adenosine release mediates the sleep-promoting effect (Satoh et al., 1996; Scammell et al., 2001).

\section{ROLE OF THE POA IN THERMOREGULATION}

Since Magoun et al. 's (1938) seminal discovery that POA warming induces hypothermia in cats, the POA has been demonstrated to be a key brain region integrating peripheral and central temperature information to control the body temperature (Nakamura, 2011; Tan and Knight, 2018). After lesioning or pharmacologically silencing the POA, rats are unable to regulate their core body temperature in response to increases $\left(35-43^{\circ} \mathrm{C}\right)$ 
or decreases $\left(-5-6^{\circ} \mathrm{C}\right)$ of the ambient temperature (Lipton, 1968; Carlisle, 1969; Satinoff et al., 1976; Van Zoeren and Stricker, 1976; Osaka, 2004; Ishiwata et al., 2005), demonstrating the necessary role of the POA for autonomous thermoregulation in response to heat or cold exposure. In contrast, POA lesions in rats do not affect behavioral thermoregulatory responses such as warmth seeking or cold seeking (Lipton, 1968; Carlisle, 1969; Satinoff and Rutstein, 1970; Roberts and Martin, 1977; Schulze et al., 1981; Almeida et al., 2006) suggesting that the POA is involved in regulating autonomous, but not behavioral thermoregulation. Warm and cold signals are detected in the skin by primary sensory ganglia and then transmitted to the dorsal horn of the spinal cord, the lateral parabrachial nucleus in the pons and finally relayed to the POA (Figure 3). External heat exposure $\left(31.5-38.5^{\circ} \mathrm{C}\right)$ in cats, mice, and rats elevates the activity of neurons in the POA (Nakayama et al., 1961, 1963; Knox et al., 1973; Scammell et al., 1993; Gong et al., 2000; Bachtell et al., 2003; Harikai et al., 2003; Bratincsák and Palkovits, 2004; Yoshida et al., 2005; Tan et al., 2016). In addition, the POA detects the local brain temperature, which increases in response to exercise and fever (Fuller et al., 1998), and local heating of the POA $\left(39-43^{\circ} \mathrm{C}\right)$ in cats and rats causes hypothermia and heat dissipation behaviors such as panting and sweating (Magoun et al., 1938; Carlisle, 1966; Carlisle and Laudenslager, 1979). A subset of POA neurons that are activated by local hypothalamic heating also become activated by warming of the skin and spinal cord suggesting

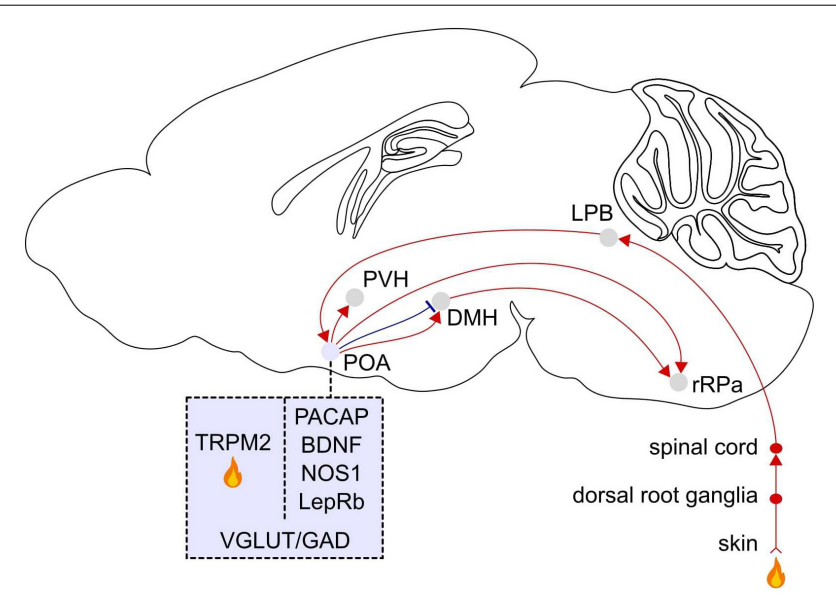

FIGURE 3 | Afferent and efferent projections of POA warm sensitive neurons. Temperature signals are detected in the skin by primary sensory ganglia and then transmitted to the dorsal horn of the spinal cord, the lateral parabrachial nucleus (LPB) in the pons, and the POA. Molecular markers for POA neurons that become activated in response to external warming are pituitary adenylate cyclase-activating polypeptides (PACAP) and brain-derived neurotrophic factor (BDNF), neuronal nitric oxide synthase (NOS1), and the leptin receptor (LepRb). The transient receptor potential M2 (TRPM2) ion channel is a local heat sensor in the POA. Thermoregulatory neurons in the POA project to the dorsomedial hypothalamus (DMH) and rostral raphe pallidus ( $\mathrm{rRPa}$ ). The $\mathrm{rRPa}$ is also strongly innervated by the DMH. TRPM2 labeled POA neurons project to the paraventricular hypothalamus $(\mathrm{PVH})$. $\mathrm{POA}$ neurons labeled with these markers co-express vesicular glutamate transporter (VGLUT) or glutamic acid decarboxylase (GAD). Sagittal brain scheme adapted from Allen Mouse Brain Atlas (@Allen Brain Atlas API. Available from http://api.brain-map.org). that central and peripheral thermal signals converge onto the POA to influence downstream thermoregulatory systems (Wit and Wang, 1968; Boulant and Hardy, 1974). POA neurons that become activated by central or peripheral warming relay temperature information to downstream effectors such as the $\mathrm{DMH}$ and rostral raphe pallidus ( $\mathrm{rRPa}$ ), which control peripheral organs to trigger autonomic responses such as suppressing thermogenesis and facilitating heat loss through sweating and vasodilation (Nakamura, 2011; Morrison, 2016; Tan and Knight, 2018; Figure 3). The rRPa is the primary endpoint in the brain that influences thermogenic pathways through the brown adipose tissue (BAT), a heat generating tissue regulating the core body temperature. Activation of the rRPa induces thermogenesis, while inhibition blocks it in rats (Morrison et al., 1999; Nakamura et al., 2002; Morrison, 2003). The rRPa is densely innervated by the $\mathrm{DMH}$, which in turn receives inputs from the POA (Hosoya et al., 1989; Nakamura, 2011). These studies suggest a critical role of the POA in integrating temperature information and triggering behavioral and autonomic responses through their central and peripheral downstream targets to adjust the body temperature.

\section{Overlapping Circuits for Sleep- and Thermoregulation}

Sleep and thermoregulation influence each other. During sleep, central autonomic and thermoregulatory activity is set to low to meet the needs for conserving energy. Sleep neurons in the POA may influence downstream thermoregulatory and central autonomic pathways to maintain this energy saving state, but the exact mechanism is not very well understood. There is also evidence that the thermoregulatory system influences sleep. The amount of sleep is influenced by the ambient temperature and a warm input from the skin and POA warming decreases the latency to sleep. On the other hand, cold exposure reduces and disrupts NREM sleep (Cerri et al., 2005), possibly because the reduced thermogenesis during sleep is not sufficient to maintain a stable core temperature.

The mechanisms for sleep and body temperature regulation anatomically and functionally overlap within the POA. Warming the POA in cats and rats induces relaxation and sleep together with enhanced slow-wave activity in the EEG (Roberts and Robinson, 1969; McGinty et al., 1994). At higher warming levels, they start to pant and stretch to dissipate heat. These studies suggest that POA neurons that become activated upon local warming may provide inputs to sleep promoting neurons to initiate and maintain sleep. The overlap between sleep and thermoregulation circuits was noted early on: the location of electrodes used to locally warm the brain in cats (Roberts and Robinson, 1969) was similar to that of electrodes implanted to promote sleep through electrical stimulation (Sterman and Clemente, 1962a) further suggesting that thermoregulatory processes in the POA may contribute to sleep regulation. To examine whether the sleep and body temperature regulation is mediated by the same POA neurons, single unit recordings combined with local temperature manipulation were performed in the POA of cats and rats. This approach revealed that a subset of POA neurons activated by local warming exhibits 
an increased discharge rate during NREM sleep compared to wakefulness (Alam et al., 1995, 1996, 1997; Szymusiak et al., 1998). Conversely, a subset of cold-sensitive neurons was more active during wakefulness than during sleep.

Several studies have further investigated the impact of POA lesions on sleep and thermoregulatory behaviors. Cats with POA lesions exhibit a significant decrease in NREM and REM sleep and cannot regulate their body temperature in response to heat (Szymusiak et al., 1991). However, the sleep disturbances were attenuated upon exposure to high ambient temperatures $\left(33^{\circ} \mathrm{C}\right)$ that also significantly increased the brain temperature. Similarly in rats, POA lesions decreased sleep and promoted preference to stay in warmer places $\left(30^{\circ} \mathrm{C}\right.$ ) (Ray et al., 2005), which in turn improved sleep. Sleep and body temperature were examined in rats after lesions of the VLPO and ventromedial preoptic area (VMPO) using ibotenic acid (Lu et al., 2000). The VLPO lesion decreased sleep without affecting the body temperature. In contrast, the VMPO lesion did not change sleep, but resulted in a significant increase in the circadian amplitude of body temperature changes. This lesion study suggests that the VMPO and VLPO may be involved in the regulation of thermoregulation and sleep, respectively.

In mice and rats, transitions to sleep are accompanied by a decrease in brain and core body temperature (Obál et al., 1985; Alföldi et al., 1990; Franken et al., 1992a,b; Hoekstra et al., 2019; Sela et al., 2021) suggesting that the brain state drives fluctuations in the body temperature. The brain and cortical temperature during different vigilance states has been further characterized in many mammalian species such as sheep, Djungarian hamsters, and monkeys (Baker and Hayward, 1968; Hayward and Baker, 1968; Deboer et al., 1994; Blessing, 2018). Sustained waking induced by sleep deprivation significantly elevated the cortical temperature in mice suggesting a causal relationship between wakefulness and cortical temperature (Hoekstra et al., 2019). Furthermore, a mathematical model used the sleep-wake sequence to simulate and predict the cortical temperature and found a significant influence of the sleep-wake state on brain temperature (Sela et al., 2021). Sleep fragmentation in mice impairs the reduction in brain temperature during sleep and instead resulted in an increase (Baud et al., 2013). These studies suggest that the transitions between sleep-wake states rapidly change the brain temperature and that a disruption of sleep counteracts the drop in temperature. The circadian rhythm also contributes to changes in body temperature (Wever, 1979; Lavie, 2001). In particular, fluctuations in body and brain temperature have been proposed to follow an ultradian rhythm, termed basic rest-activity cycle (BRAC) (Blessing and Ootsuka, 2016; Blessing, 2018; Goh et al., 2019). Increases in body and brain temperature are shortly followed by BAT thermogenesis in rats and occur approximately every 1-2 h (Ootsuka et al., 2009). The behavioral activity, arterial pressure, heart rate as well as metabolic rate also exhibit an ultradian fluctuations in synchrony with the rest-activity cycle. The role of the POA in controlling the ultradian and circadian regulation of sleep-wake states and temperature is not well understood. POA neurons regulating sleep and/or body temperature may receive circadian signals indirectly from the suprachiasmatic nucleus (SCN) via subparaventricular zone or DMH (Lu et al., 2001; Chou et al., 2002; Deurveilher et al., 2002). However, the sleep-wake state induced changes in brain temperature remained intact in SCN lesioned rats suggesting that the relationship between ultradian changes of body temperature and sleep is independent of circadian clock (Baker et al., 2005). Even in constant darkness, the variations in cortical temperature in rats are mainly determined by changes of sleep-wake states suggesting that the temperature rhythm is not entrained by the light-dark cycle (Franken et al., 1992b). These studies suggest, to a large extent, that the body temperature fluctuations are influenced by sleep-wake states independently of circadian rhythmicity of the SCN. In future studies, it would be interesting to test whether vigilance stateinduced body temperature fluctuations may be mediated by the POA sleep-promoting neurons that regulate downstream thermoregulatory pathways.

\section{Molecular Characterization of POA Thermoregulatory Neurons and Their Pathways}

Electrophysiological recordings followed by single cell transcriptomics revealed the expression pattern of neurotransmitters, neuromodulators, receptors, and ion channels in the electrophysiologically identified warm sensitive neurons (WSNs) of mice (Eberwine and Bartfai, 2011). This effort uncovered an unexpected degree of molecular heterogeneity in WSNs, which have been previously thought to form a rather homogeneous population based on electrophysiological recordings and immunohistochemical analysis (Nakayama et al., 1961, 1963; Boulant, 1998). Interestingly, WSNs express various neuropeptides such as galanin, TAC1, somatostatin, and prodynorphin (Eberwine and Bartfai, 2011), and POA neurons expressing these markers have been shown to promote sleep (Xu et al., 2015; Chung et al., 2017; Kroeger et al., 2018; Ma et al., 2019). Furthermore, injecting these neuropeptides into the POA or their axonal projection targets such as the $\mathrm{DMH}$ and $\mathrm{rRPa}$ induces hyperthermia (Eberwine and Bartfai, 2011), indicating that they are likely secreted in these postsynaptic regions. Single cell transcriptomics further revealed the expression of multiple ion channels and G protein-coupled receptors (GPCRs) including orphan GPCRs (Eberwine and Bartfai, 2011). Given the availability of agonists, antagonists, and modulators for these receptors and channels, their pharmacological roles in the POA can be further investigated to uncover how WSNs integrate various signals to regulate the body temperature.

To identify specific molecular markers for POA neurons controlling the body temperature, phosphoTRAP was employed to profile activated neurons in mice (Knight et al., 2012; Tan et al., 2016). Neural activation leads to the phosphorylation of the ribosomal protein S6, which can be captured to sequence mRNAs. Mice were exposed to warm temperature $\left(37^{\circ} \mathrm{C}\right)$, and subsequently activated neurons in the anterior VMPO were sequenced. Gene profiling of these neurons revealed that they specifically express the neuropeptides pituitary adenylate cyclaseactivating polypeptide (Adcyap1, also known as PACAP) and brain-derived neurotrophic factor $(B d n f)\left(\mathrm{VMPO}{ }^{\mathrm{PACAP}} / \mathrm{BDNF}\right)$ 
(Tan et al., 2016). Fiber photometry recordings showed that $\mathrm{VMPO}^{\mathrm{PACAP} / \mathrm{BDNF}}$ neurons are activated in response to warm ambient temperatures $\left(30-42^{\circ} \mathrm{C}\right)$ or injection of capsaicin, a transient receptor potential (TRP) V1 agonist, but are nonresponsive to cold temperatures, the TRP M8 agonist icilin or several non-thermal stimuli. Whole-cell patch clamp recordings from acute brain slices showed that $\mathrm{VMPO} \mathrm{PACAP} / \mathrm{BDNF}^{\mathrm{P}}$ neurons are not more thermosensitive than neighboring cells indicating they may not be directly activated by local heat. The peripheral injection of capsaicin rapidly activated $\mathrm{VMPO}^{\mathrm{PACAP} / \mathrm{BDNF}}$ neurons suggesting that TRPV1 sensory fibers may influence their activity. These results suggest that $\mathrm{VMPO}^{\mathrm{PACAP} / \mathrm{BDNF}}$ neurons receive temperature signals from peripheral sensory neurons. Optogenetic stimulation of these neurons promoted hypothermia and induced thermoregulatory behaviors such as nest building. The majority of $\mathrm{VMPO}{ }^{\mathrm{PACAP} / \mathrm{BDNF}}$ neurons are GABAergic, and their major projection target is the $\mathrm{DMH}$ (Figure 3). Taken together, $\mathrm{VMPO}{ }^{\mathrm{PACAP} / \mathrm{BDNF}}$ neurons are activated by ambient warmth and coordinate the behavioral and autonomic responses to heat.

Another study discovered the TRPM2 ion channel acts as a heat sensor and thus serves as a marker for WSNs in the POA of mice (Song et al., 2016). TRPM2 is a temperature responsive ion channel expressed in a subpopulation of POA neurons and detects increased temperature in brain slices $\left(38^{\circ} \mathrm{C}\right)$ and prostaglandin $\mathrm{E} 2\left(\mathrm{PGE}_{2}\right)$-induced fever in vivo. TRPM2 is broadly expressed throughout the POA, whereas PACAP/BDNF expression is localized within the VMPO in mice (Tan et al., 2016). Chemogenetic activation and inhibition of TRPM2-POA neurons decreased and increased the body temperature, respectively. About $30 \%$ of TRPM2 neurons are excitatory (Song et al., 2016). Activation of POA excitatory (Vglut2) neurons, but not inhibitory (Vgat) neurons, promoted hypothermia indicating that the hypothermic effect of activating POA TRPM2 neurons are mediated by excitatory signals from POA Vglut2-TRPM2 neurons. One of their projection targets is corticotropin releasing hormone neurons in the paraventricular hypothalamus (PVH), which is part of the hypothalamic-pituitary-adrenal stress response system and also activated by fever (Matsuoka et al., 2003; Figure 3).

The body temperature is tightly interconnected with energy expenditure. Leptin signaling in the brain through its receptor (LepRb) has been shown to mediate energy expenditure, and a subpopulation of POA neurons expressing LepRb (LepRb ${ }^{\mathrm{POA}}$ neurons) is involved in thermoregulation of mice ( $\mathrm{Yu}$ et al., 2016). LepRb ${ }^{\mathrm{POA}}$ neurons are activated in response to warm temperatures $\left(30^{\circ} \mathrm{C}\right)$, but not upon cold exposure $\left(4^{\circ} \mathrm{C}\right)$. Activation of LepRb ${ }^{\mathrm{POA}}$ neurons in mice decreased the core body temperature, locomotor activity, and energy expenditure as measured by their oxygen consumption. In addition, stimulation of LepRb ${ }^{\mathrm{POA}}$ neurons induced postural extension, a behavioral response to high ambient temperature. The LepRb ${ }^{\mathrm{POA}}$ neurons that are responsible for thermoregulation are mainly glutamatergic and send stimulatory signals to the $\mathrm{DMH} /$ dorsal hypothalamic area and rRPa in mice (Zhang et al., 2011; Yu et al., 2016; Figure 3).
Previous studies employing c-Fos dependent activity tagging tested whether reactivating neurons that are activated by sleep or warmth promote sleep and/or hypothermia. Capturing POA neurons that are activated during sleep rebound and reactivating them promoted both sleep and hypothermia in mice (Zhang et al., 2015). Another study identified POA neurons that are differentially involved in sleep and/or body cooling (Harding et al., 2018). External warming $\left(32^{\circ} \mathrm{C}\right)$ activated two groups of neurons in the $\mathrm{MnPO} /$ medial preoptic (MPO) hypothalamic area in mice. The tagged neurons were nitrergic/glutamatergic in the MnPO-MPO and GABAergic in the MPO and their reactivation promoted sleep together with hypothermia or only NREM sleep, respectively. This study demonstrated that the circuits for sleep and thermoregulation overlap, at least partially, in the MnPO-MPO neuronal nitric oxide synthase (NOS1) expressing neurons whereas sleep is instead selectively regulated by MPO-GABAergic neurons.

Galanin neurons in the POA have also been shown to be important for hypothermia associated with NREM sleep in mice (Ma et al., 2019). Chemogenetic activation of galanin neurons induces hypothermia (Kroeger et al., 2018; Ma et al., 2019), suggesting a role in promoting heat loss. Ablating galanin neurons significantly elevated the core body temperature and prevented hypothermia induced by injection of the $\alpha 2$-adrenergic agonist dexmedetomidine (Ma et al., 2019). Surprisingly, fiber photometry recordings showed that Galanin neurons are not activated in response to warm ambient temperatures $\left(25-50^{\circ} \mathrm{C}\right)$ (Tan et al., 2016). Given that the galanin population includes both GABAergic and glutamatergic neurons in mice (Moffitt et al., 2018), it is unknown whether GABAergic or glutamatergic galanin neurons or both of these subpopulations regulate the body temperature.

Torpor and hibernation are adaptive behaviors that allow homeothermic animals to reduce their body temperature, metabolic rate, and activity in order to survive in harsh environments with low food supply or cold temperatures (Heller and Ruby, 2004; Geiser, 2013). The laboratory mouse Mus musculus is able to undergo short-term shallow torpor by lowering its body temperature and metabolism, resulting in reduced energy consumption (Hudson and Scott, 1979). Two recent studies identified specific circuits in the POA that regulate torpor. Takahashi et al. (2020) found that neurons expressing pyroglutamylated Rfamide peptide (QRFP), in the AVPe and medial preoptic area (MPA) induce a long-lasting hypothermic and hypometabolic state similar to hibernation in mice. The QRFP neurons in the AVPe/MPA are both GABAergic and glutamatergic, and their projections to the $\mathrm{DMH}$ mediate the hibernation-like state. Activation of QRFP neurons decreases the body temperature and oxygen consumption, while keeping the metabolism at a low rate. No tissue damage was found following the hibernation-like state, and mice spontaneously recovered without external stimulation. Furthermore, activation of calcium/calmodulin-dependent protein kinase II expressing neurons including QRFP neurons in the AVPe/MPA (Takahashi et al., 2020) and injection of the glutamatergic agonist $N$-methylD-aspartic acid (NMDA) into the MPA or VLPO (Conceição et al., 2019) also induced a hypometabolic state in rats, a species 
that does not enter hibernation and daily torpor, indicating that rats share with mice circuits underlying the regulation of hypothermia and hypometabolism. QRFP has also been implicated in regulating food intake, sympathetic regulation, and anxiety and is expressed in other hypothalamic regions (Takayasu et al., 2006; Okamoto et al., 2016). Hrvatin et al. (2020) identified a population of Adcyap1-positive cells in the anterior and ventral portions of the medial and lateral preoptic area (avMLPA ${ }^{\text {Adcyap } 1}$ ), which control fasting-induced torpor in mice. Activating avMLPA ${ }^{\text {Adcyap1 }}$ neurons decreased the body temperature and motor activity whereas inhibition disrupted torpor induction, maintenance, and arousal. Fiber photometry showed that their activity increased in response to cold exposure $\left(10^{\circ} \mathrm{C}\right)$ and changed during the torpor-like state; their baseline level decreased, while the frequency of $\mathrm{Ca}^{2+}$-dependent events increased. Inducing a torpor-like state in non-torpid species such as human patients experiencing trauma from cardiac arrest, organ transplantation, major cardiac, and brain surgery could provide a tool to reduce organ damage (Aslami and Juffermans, 2010; Bouma et al., 2012). Central pharmacological activation of the $\mathrm{A} 1$ adenosine receptor was shown to induce hypothermic, torpor-like states in rats when exposed to cold ambient temperatures $\left(15^{\circ} \mathrm{C}\right)$ suggesting the potential therapeutic role of targeting this receptor to induce a hypothermic state in humans (Tupone et al., 2013, 2016).

Fever, a significant body temperature increase in response to infections and inflammation is an evolutionarily conserved phenomenon and necessary to help the immune system fight infections and inhibit the growth of microorganisms (Blomqvist and Engblom, 2018). During this state, the presence of bacteria or viruses is sensed by immune cells in the blood leading to the production of cytokines and prostaglandins (Evans et al., 2015). The POA is also activated by fever accompanying an enhanced immune response. Injection of lipopolysaccharide (LPS), common bacterial cell walls, triggers immune responses including fever and increases the number of c-Fos-labeled neurons in the POA in rats, especially within the ventromedial part, indicating a role in initiating the fever response (Elmquist et al., 1996). LPS-induced fever is absent in mice deficient in microsomal prostaglandin $\mathrm{E}$ synthase-1 (mPGES-1), which lack $\mathrm{PGE}_{2}$ synthesis, suggesting that fever is mediated by $\mathrm{PGE}_{2}$ (Engblom et al., 2003). Microinjection of $\mathrm{PGE}_{2}$ into the VMPO induces fever and c-Fos expression in rats, demonstrating that the VMPO is an important site through which $\mathrm{PGE}_{2}$ promotes fever (Scammell et al., 1996). In particular, $\mathrm{PGE}_{2}$ has been shown to act on warm-sensitive thermoregulatory neurons in the hypothalamus (Saper and Breder, 1994; Saper et al., 2012). PGE 2 activates one of its receptors, EP3R, expressed in excitatory VMPO/MnPO neurons to mediate the fever response in mice (Machado et al., 2020). LPS-induced fever is also mediated by $\mathrm{PGE}_{2}$ action through the $\mathrm{EP} 3 \mathrm{R}$ receptors in $\mathrm{VMPO} / \mathrm{MnPO}$ glutamatergic neurons and is eliminated when these neurons are ablated. Glutamatergic EP3R-expressing POA neurons directly project to the $\mathrm{rRPa}$ and this pathway may mediate inflammatory fever (Yoshida et al., 2009; Machado et al., 2020). Taken together, these studies on torpor, energy homeostasis, and fever revealed a variety of molecular markers that specifically label thermoregulatory neurons in the POA.

\section{DISCUSSION}

The POA comprises many subdivisions, and the recent identification of novel molecular markers that specifically label neurons regulating sleep or body temperature helped to precisely define the subregions and cell types controlling these fundamental behaviors. Furthermore, newly developed tools greatly improved the temporal and spatial resolution for recording and manipulating these neurons providing important insights into the underlying circuit mechanisms (Figure 1).

However, the extent of anatomical overlap between warmsensitive and sleep-promoting POA neurons is still largely unknown. Consequently, the projection pattern of such neurons and their interaction with other regions involved in sleep and temperature control is still unknown. An interesting hypothesis to test in future studies is whether neurons involved in both behaviors send axonal projections to both sleep and temperatureregulatory downstream areas. The location of newly identified sleep and thermoregulatory neurons partially overlap. Previous studies indicated that a subset of POA neurons activated by local warming becomes activated during NREM sleep (Alam et al., 1995, 1996, 1997; Szymusiak et al., 1998). It is unknown whether the coordination of sleep and thermoregulation is mediated by neurons that regulate both behaviors, or whether it is the result of local or long-range interactions between separate sets of POA sleep and thermoregulatory neurons. Recent studies provided a list of molecular markers that label sleep and/or thermoregulatory neurons in the POA of mice (Figures 2, 3). Systematic investigation of their anatomical overlap, local synaptic interactions and activity during sleep and in response to local and external temperature changes will help to understand how sleep and thermoregulation are orchestrated at the circuit level. Another possible circuit motif underlying the coordination of both behaviors may be common postsynaptic targets. Given that the body temperature rapidly drops at the onset of NREM sleep, a subset of NREM-active cells may project to areas involved in temperature regulation such as the medullary sympathetic premotor neurons that regulate body temperature and peripheral vasculature (Nakamura, 2011). Elucidating the extent to which the sleep-regulatory neurons target critical nodes of the thermoregulatory pathway such as the DMH and rRPa or the warm-sensitive neurons may in turn innervate regions controlling sleep will greatly enhance our understanding of the coordinated regulation of sleep and body temperature. Furthermore, given that the majority of novel molecular markers has been identified in mice for which most recent techniques are available and the thermoregulatory and sleep behaviors vary across species, it is important to elucidate the circuits regulating these behaviors also in other animals than mice and to identify conserved mechanisms.

Preoptic area of the hypothalamus sleep and thermoregulatory neurons express a variety of peptidergic markers as well as receptors and channels (Eberwine and Bartfai, 2011; 
Moffitt et al., 2018). An important area of future research is to investigate the functional role of these peptides and the signaling pathways initiated by these receptors/channels using recently developed tools such as sensors to detect the release of neurotransmitters and modulators or CRISPR/Cas9 gene editing to interrogate gene function within molecularly-defined neurons (Yamaguchi et al., 2018; Jing et al., 2019; Sabatini and Tian, 2020).

In addition to thermoregulation, sleep is also closely interconnected with metabolism. During NREM sleep, the energy metabolism is strongly reduced. Chronic sleep fragmentation in mice prevents the reduction of the brain temperature during sleep and leads to increased food intake and glucose intolerance suggesting that poor-quality sleep may contribute to development of metabolic dysfunctions (Baud et al., 2013). Similarly, laboratory and epidemiologic studies suggest that poor sleep might promote the development of metabolic disorders (Spiegel et al., 2009). Local warming of the POA reduces feeding and POA lesions disrupt feeding in response to changes in the ambient temperature, suggesting an overlap of the mechanisms regulating metabolism and thermoregulation within the POA (Andersson and Larsson, 1961; Hamilton and Brobeck, 1966). LepRb expressing neurons in the POA become activated after exposure to warm and neutral ambient temperatures $\left(22-30^{\circ} \mathrm{C}\right)$ and modulate feeding and body weight by controlling BAT thermogenesis demonstrating their role in energy homeostasis and body weight regulation in a temperature-dependent manner (Yu et al., 2016). Infusion of glucose to the POA promotes NREM sleep by increasing the activity of sleep-promoting neurons further suggesting the link between sleep and metabolism (Varin et al., 2015). The POA sleep- and/or thermo-regulatory neurons may project to downstream circuits involved in feeding and energy expenditure such as $\mathrm{LH}$ to regulate the overall energy metabolism. In addition to sleep, energy metabolism is also influenced by the circadian rhythm. For example, mice with targeted disruption of the core clock gene Clock develop obesity and metabolic syndromes suggesting that this circadian clock gene plays an important role in energy balance (Turek et al., 2005). For future studies, it would be interesting to test to what

\section{REFERENCES}

Alam, M. A., Kumar, S., McGinty, D., Alam, M. N., and Szymusiak, R. (2014). Neuronal activity in the preoptic hypothalamus during sleep deprivation and recovery sleep. J. Neurophysiol. 111, 287-299. doi: 10.1152/jn.00504.2013

Alam, M. N., McGinty, D., and Szymusiak, R. (1995). Neuronal discharge of preoptic/anterior hypothalamic thermosensitive neurons: relation to NREM sleep. Am. J. Physiol. 269, R1240-R1249. doi: 10.1152/ajpregu.1995.269.5. $\mathrm{R} 1240$

Alam, M. N., McGinty, D., and Szymusiak, R. (1996). Preoptic/anterior hypothalamic neurons: thermosensitivity in wakefulness and non rapid eye movement sleep. Brain Res. 718, 76-82. doi: 10.1016/0006-8993(96)00035-2

Alam, M. N., McGinty, D., and Szymusiak, R. (1997). Thermosensitive neurons of the diagonal band in rats: relation to wakefulness and non-rapid eye movement sleep. Brain Res. 752, 81-89. doi: 10.1016/s0006-8993(96)01452-7

Alföldi, P., Rubicsek, G., Cserni, G., and Obál, F. (1990). Brain and core temperatures and peripheral vasomotion during sleep and wakefulness at various ambient temperatures in the rat. Pflugers Arch. 417, 336-341. doi: 10.1007/BF00371001 extent circadian influences on the metabolism are mediated by indirect inputs from the SCN to the POA sleep neurons (Lu et al., 2001; Chou et al., 2002; Deurveilher et al., 2002).

Different types of sleep disorders, especially those associated with aging, may be influenced by altered body temperature rhythms or dysregulation of vasodilation resulting in an impairment to prepare the body for sleep (Foley et al., 1995; Ozaki et al., 1996; Pache et al., 2001; Watanabe et al., 2003; Fronczek et al., 2006; Kräuchi, 2007; Lack et al., 2008; Raymann and Van Someren, 2008). Delayed temperature rhythms or dysfunctions in sensing and transferring temperature information to the neurons controlling sleep within the POA may contribute to attenuate the sleep onset in the elderly. Elucidating how POA neurons receiving peripheral temperature signals interact with the sleep-promoting neurons and integrate circadian rhythms, and how these circuits become dysfunctional with aging will greatly improve our current therapeutics for sleep disorders.

\section{AUTHOR CONTRIBUTIONS}

Both authors wrote the manuscript, made the figures, contributed to the article and approved the submitted version.

\section{FUNDING}

This work was supported by NIH/NINDS R01 NS110865, Alfred P. Sloan Research Fellowship in Neuroscience, The Hartwell Individual Biomedical Research Award, The McCabe Fund Award, The Whitehall Foundation Grant, Simons Foundation Pilot Award, NARSAD Young Investigator Award, and Eagles Autism Challenge Pilot Grant to SC.

\section{ACKNOWLEDGMENTS}

We thank Franz Weber for proofreading the manuscript.

Almeida, M. C., Steiner, A. A., Branco, L. G. S., and Romanovsky, A. A. (2006) Neural substrate of cold-seeking behavior in endotoxin shock. PLoS One 1:e1. doi: 10.1371/journal.pone.0000001

Andersson, B., and Larsson, B. (1961). Influence of local temperature changes in the preoptic area and rostral hypothalamus on the regulation of food and water intake. Acta Physiol. Scand. 52, 75-89. doi: 10.1111/j.1748-1716.1961.tb02203.x

Aslami, H., and Juffermans, N. P. (2010). Induction of a hypometabolic state during critical illness - a new concept in the ICU? Neth. J. Med. 68, 190-198.

Aston-Jones, G., and Bloom, F. E. (1981). Activity of norepinephrine-containing locus coeruleus neurons in behaving rats anticipates fluctuations in the sleepwaking cycle. J. Neurosci. 1, 876-886. doi: 10.1523/JNEUROSCI.01-08-00876. 1981

Bachtell, R. K., Tsivkovskaia, N. O., and Ryabinin, A. E. (2003). Identification of temperature-sensitive neural circuits in mice using c-Fos expression mapping. Brain Res. 960, 157-164. doi: 10.1016/s0006-8993(02)03807-6

Baker, F. C., Angara, C., Szymusiak, R., and McGinty, D. (2005). Persistence of sleep-temperature coupling after suprachiasmatic nuclei lesions in rats. Am. J. Physiol. Regul. Integr. Comp. Physiol. 289, R827-R838. doi: 10.1152/ajpregu. 00093.2005 
Baker, M. A., and Hayward, J. N. (1968). The influence of the nasal mucosa and the carotid rete upon hypothalamic temperature in sheep. J. Physiol. 198, 561-579. doi: 10.1113/jphysiol.1968.sp008626

Baud, M. O., Magistretti, P. J., and Petit, J.-M. (2013). Sustained sleep fragmentation affects brain temperature, food intake and glucose tolerance in mice. J. Sleep Res. 22, 3-12. doi: 10.1111/j.1365-2869.2012.01029.x

Berger, R. J. (1984). Slow wave sleep, shallow torpor and hibernation: homologous states of diminished metabolism and body temperature. Biol. Psychol. 19, 305-326. doi: 10.1016/0301-0511(84)90045-0

Blessing, W., and Ootsuka, Y. (2016). Timing of activities of daily life is jaggy: how episodic ultradian changes in body and brain temperature are integrated into this process. Temp. Multidiscip. Biomed. J. 3, 371-383. doi: 10.1080/23328940. 2016.1177159

Blessing, W. W. (2018). Thermoregulation and the ultradian basic rest-activity cycle. Handb. Clin. Neurol. 156, 367-375. doi: 10.1016/B978-0-444-63912-7. 00022-9

Blomqvist, A., and Engblom, D. (2018). Neural mechanisms of inflammationinduced fever. Neurosci. Rev. J. Bringing Neurobiol. Neurol. Psychiatry 24, 381-399. doi: 10.1177/1073858418760481

Boulant, J. A. (1998). Hypothalamic neurons. Mechanisms of sensitivity to temperature. Ann. N. Y. Acad. Sci. 856, 108-115. doi: 10.1111/j.1749-6632.1998. tb08319.x

Boulant, J. A., and Hardy, J. D. (1974). The effect of spinal and skin temperatures on the firing rate and thermosensitivity of preoptic neurones. J. Physiol. 240, 639-660. doi: 10.1113/jphysiol.1974.sp010627

Bouma, H. R., Verhaag, E. M., Otis, J. P., Heldmaier, G., Swoap, S. J., Strijkstra, A. M., et al. (2012). Induction of torpor: mimicking natural metabolic suppression for biomedical applications. J. Cell. Physiol. 227, 1285-1290. doi: $10.1002 /$ jcp. 22850

Bratincsák, A., and Palkovits, M. (2004). Activation of brain areas in rat following warm and cold ambient exposure. Neuroscience 127, 385-397. doi: 10.1016/j. neuroscience.2004.05.016

Breton-Provencher, V., and Sur, M. (2019). Active control of arousal by a locus coeruleus GABAergic circuit. Nat. Neurosci. 22, 218-228. doi: 10.1038/s41593018-0305-z

Bunnell, D. E., Agnew, J. A., Horvath, S. M., Jopson, L., and Wills, M. (1988). Passive body heating and sleep: influence of proximity to sleep. Sleep 11, 210-219.

Campbell, S. S., and Broughton, R. J. (1994). Rapid decline in body temperature before sleep: fluffing the physiological pillow? Chronobiol. Int. 11, 126-131. doi: 10.3109/07420529409055899

Carlisle, H. J. (1966). Behavioural significance of hypothalamic temperaturesensitive cells. Nature 209, 1324-1325. doi: 10.1038/2091324a0

Carlisle, H. J. (1969). Effect of preoptic and anterior hypothalamic lesions on behavioral thermoregulation in the cold. J. Comp. Physiol. Psychol. 69, 391-402. doi: $10.1037 / \mathrm{h} 0028170$

Carlisle, H. J., and Laudenslager, M. L. (1979). Observations on the thermoregulatory effects of preoptic warming in rats. Physiol. Behav. 23, 723-732. doi: 10.1016/0031-9384(79)90166-5

Cerri, M., Ocampo-Garces, A., Amici, R., Baracchi, F., Capitani, P., Jones, C. A., et al. (2005). Cold exposure and sleep in the rat: effects on sleep architecture and the electroencephalogram. Sleep 28, 694-705. doi: 10.1093/sleep/28.6.694

Chen, K.-S., Xu, M., Zhang, Z., Chang, W.-C., Gaj, T., Schaffer, D. V., et al. (2018). A Hypothalamic switch for REM and Non-REM Sleep. Neuron 97, 1168-1176.e4. doi: 10.1016/j.neuron.2018.02.005

Chou, T. C., Bjorkum, A. A., Gaus, S. E., Lu, J., Scammell, T. E., and Saper, C. B. (2002). Afferents to the ventrolateral preoptic nucleus. J. Neurosci. 22, 977-990. doi: 10.1523/JNEUROSCI.22-03-00977.2002

Chung, S., Weber, F., Zhong, P., Tan, C. L., Nguyen, T., Beier, K. T., et al. (2017). Identification of preoptic sleep neurons using retrograde labeling and gene profiling. Nature 545, 477-481. doi: 10.1038/nature22350

Conceição, E. P. S., Madden, C. J., and Morrison, S. F. (2019). Neurons in the rat ventral lateral preoptic area are essential for the warm-evoked inhibition of brown adipose tissue and shivering thermogenesis. Acta Physiol. 225:e13213. doi: 10.1111/apha.13213

Deboer, T., Franken, P., and Tobler, I. (1994). Sleep and cortical temperature in the Djungarian hamster under baseline conditions and after sleep deprivation. J. Comp. Physiol. A 174, 145-155. doi: 10.1007/BF00193782
Deisseroth, K. (2015). Optogenetics: 10 years of microbial opsins in neuroscience. Nat. Neurosci. 18, 1213-1225. doi: 10.1038/nn.4091

Deisseroth, K., and Hegemann, P. (2017). The form and function of channelrhodopsin. Science 357:eaan5544. doi: 10.1126/science.aan5544

Deurveilher, S., Burns, J., and Semba, K. (2002). Indirect projections from the suprachiasmatic nucleus to the ventrolateral preoptic nucleus: a dual tracttracing study in rat. Eur. J. Neurosci. 16, 1195-1213. doi: 10.1046/j.1460-9568. 2002.02196.x

Dulac, C., O'Connell, L. A., and Wu, Z. (2014). Neural control of maternal and paternal behaviors. Science 345, 765-770. doi: 10.1126/science.1253291

Eberwine, J., and Bartfai, T. (2011). Single cell transcriptomics of hypothalamic warm sensitive neurons that control core body temperature and fever response. Pharmacol. Ther. 129, 241-259. doi: 10.1016/j.pharmthera.2010.09.010

Elmquist, J. K., Scammell, T. E., Jacobson, C. D., and Saper, C. B. (1996). Distribution of Fos-like immunoreactivity in the rat brain following intravenous lipopolysaccharide administration. J. Comp. Neurol. 371, 85-103.

Engblom, D., Saha, S., Engström, L., Westman, M., Audoly, L. P., Jakobsson, P.-J., et al. (2003). Microsomal prostaglandin E synthase-1 is the central switch during immune-induced pyresis. Nat. Neurosci. 6, 1137-1138. doi: 10.1038/nn1137

Evans, S. S., Repasky, E. A., and Fisher, D. T. (2015). Fever and the thermal regulation of immunity: the immune system feels the heat. Nat. Rev. Immunol. 15, 335-349. doi: 10.1038/nri3843

Foley, D. J., Monjan, A. A., Brown, S. L., Simonsick, E. M., Wallace, R. B., and Blazer, D. G. (1995). Sleep complaints among elderly persons: an epidemiologic study of three communities. Sleep 18, 425-432. doi: 10.1093/sleep/18.6.425

Franken, P., Tobler, I., and Borbély, A. A. (1992a). Cortical temperature and EEG slow-wave activity in the rat: analysis of vigilance state related changes. Pflügers Arch. 420, 500-507. doi: 10.1007/BF00374625

Franken, P., Tobler, I., and Borbély, A. A. (1992b). Sleep and waking have a major effect on the 24-hr rhythm of cortical temperature in the rat. J. Biol. Rhythms 7, 341-352. doi: 10.1177/074873049200700407

Fronczek, R., Overeem, S., Lammers, G. J., van Dijk, J. G., and Van Someren, E. J. W. (2006). Altered skin-temperature regulation in narcolepsy relates to sleep propensity. Sleep 29, 1444-1449. doi: 10.1093/sleep/29.11.1444

Fuller, A., Carter, R. N., and Mitchell, D. (1998). Brain and abdominal temperatures at fatigue in rats exercising in the heat. J. Appl. Physiol. 877-883. doi: 10.1152/ jappl.1998.84.3.877

Gallopin, T., Fort, P., Eggermann, E., Cauli, B., Luppi, P. H., Rossier, J., et al. (2000). Identification of sleep-promoting neurons in vitro. Nature 404, 992-995. doi: 10.1038/35010109

Gallopin, T., Luppi, P.-H., Cauli, B., Urade, Y., Rossier, J., Hayaishi, O., et al. (2005). The endogenous somnogen adenosine excites a subset of sleep-promoting neurons via A2A receptors in the ventrolateral preoptic nucleus. Neuroscience 134, 1377-1390. doi: 10.1016/j.neuroscience.2005.05.045

Gaus, S. E., Strecker, R. E., Tate, B. A., Parker, R. A., and Saper, C. B. (2002). Ventrolateral preoptic nucleus contains sleep-active, galaninergic neurons in multiple mammalian species. Neuroscience 115, 285-294.

Geiser, F. (2013). Hibernation. Curr. Biol. 23, R188-R193. doi: 10.1016/j.cub.2013. 01.062

Gerashchenko, D., Beuckmann, C. T., Kanaoka, Y., Eguchi, N., Gordon, W. C., Urade, Y., et al. (1998). Dominant expression of rat prostanoid DP receptor mRNA in leptomeninges, inner segments of photoreceptor cells, iris epithelium, and ciliary processes. J. Neurochem. 71, 937-945. doi: 10.1046/j.1471-4159. 1998.71030937.x

Gervasoni, D., Peyron, C., Rampon, C., Barbagli, B., Chouvet, G., Urbain, N., et al. (2000). Role and origin of the GABAergic innervation of Dorsal Raphe serotonergic neurons. J. Neurosci. 20, 4217-4225. doi: 10.1523/JNEUROSCI.2011-04217.2000

Goh, G. H., Maloney, S. K., Mark, P. J., and Blache, D. (2019). Episodic ultradian events-ultradian rhythms. Biology 8:15. doi: 10.3390/biology8010015

Gong, H., McGinty, D., Guzman-Marin, R., Chew, K.-T., Stewart, D., and Szymusiak, R. (2004). Activation of c-fos in GABAergic neurones in the preoptic area during sleep and in response to sleep deprivation. J. Physiol. 556, 935-946. doi: 10.1113/jphysiol.2003.056622

Gong, H., Szymusiak, R., King, J., Steininger, T., and McGinty, D. (2000). Sleeprelated c-Fos protein expression in the preoptic hypothalamus: effects of ambient warming. Am. J. Physiol. Regul. Integr. Comp. Physiol. 279, R2079R2088. doi: 10.1152/ajpregu.2000.279.6.R2079 
Gordon, C. J., Aydin, C., Repasky, E. A., Kokolus, K. M., Dheyongera, G., and Johnstone, A. F. M. (2014). Behaviorally mediated, warm adaptation: a physiological strategy when mice behaviorally thermoregulate. J. Therm. Biol. 44, 41-46. doi: 10.1016/j.jtherbio.2014.06.006

Grosenick, L., Marshel, J. H., and Deisseroth, K. (2015). Closed-loop and activityguided optogenetic control. Neuron 86, 106-139. doi: 10.1016/j.neuron.2015. 03.034

Guzmán-Marín, R., Alam, M. N., Szymusiak, R., Drucker-Colín, R., Gong, H., and McGinty, D. (2000). Discharge modulation of rat dorsal raphe neurons during sleep and waking: effects of preoptic/basal forebrain warming. Brain Res. 875, 23-34. doi: 10.1016/S0006-8993(00)02561-0

Gvilia, I., Turner, A., McGinty, D., and Szymusiak, R. (2006). Preoptic area neurons and the homeostatic regulation of rapid eye movement sleep. J. Neurosci. 26, 3037-3044. doi: 10.1523/JNEUROSCI.4827-05.2006

Hamilton, C. L., and Brobeck, J. R. (1966). Food intake and activity of rats with rostral hypothalamic lesions. Proc. Soc. Exp. Biol. Med. 122, 270-272. doi: 10.3181/00379727-122-31108

Harding, E. C., Yu, X., Miao, A., Andrews, N., Ma, Y., Ye, Z., et al. (2018). A neuronal hub binding sleep initiation and body cooling in response to a warm external stimulus. Curr. Biol. 28, 2263-2273.e4. doi: 10.1016/j.cub.2018.05.054

Harikai, N., Tomogane, K., Sugawara, T., and Tashiro, S. (2003). Differences in hypothalamic Fos expressions between two heat stress conditions in conscious mice. Brain Res. Bull. 61, 617-626. doi: 10.1016/j.brainresbull.2003.07.001

Hayward, J. N., and Baker, M. A. (1968). Role of cerebral arterial blood in the regulation of brain temperature in the monkey. Am. J. Physiol. 215, 389-403. doi: 10.1152/ajplegacy.1968.215.2.389

Heller, H. C., and Ruby, N. F. (2004). Sleep and circadian rhythms in mammalian torpor. Annu. Rev. Physiol. 66, 275-289. doi: 10.1146/annurev.physiol.66. 032102.115313

Heym, J., Steinfels, G. F., and Jacobs, B. L. (1982). Activity of serotonin-containing neurons in the nucleus raphe pallidus of freely moving cats. Brain Res. 251, 259-276. doi: 10.1016/0006-8993(82)90743-0

Hoekstra, M. M., Emmenegger, Y., Hubbard, J., and Franken, P. (2019). Coldinducible RNA-binding protein (CIRBP) adjusts clock-gene expression and REM-sleep recovery following sleep deprivation. eLife 8:e43400. doi: 10.7554/ eLife. 43400

Horne, J. A., and Shackell, B. S. (1987). Slow wave sleep elevations after body heating: proximity to sleep and effects of aspirin. Sleep 10, 383-392. doi: 10. 1093/sleep/10.4.383

Horne, J. A., and Staff, L. H. (1983). Exercise and sleep: body-heating effects. Sleep 6, 36-46. doi: 10.1093/sleep/6.1.36

Hosoya, Y., Sugiura, Y., Zhang, F. Z., Ito, R., and Kohno, K. (1989). Direct projection from the dorsal hypothalamic area to the nucleus raphe pallidus: a study using anterograde transport with Phaseolus vulgaris leucoagglutinin in the rat. Exp. Brain Res. 75, 40-46. doi: 10.1007/BF00248528

Hrvatin, S., Sun, S., Wilcox, O. F., Yao, H., Lavin-Peter, A. J., Cicconet, M., et al. (2020). Neurons that regulate mouse torpor. Nature 583, 115-121. doi: 10.1038/ s41586-020-2387-5

Hsieh, K.-C., Gvilia, I., Kumar, S., Uschakov, A., McGinty, D., Alam, M. N., et al. (2011). c-Fos expression in neurons projecting from the preoptic and lateral hypothalamic areas to the ventrolateral periaqueductal gray in relation to sleep states. Neuroscience 188, 55-67. doi: 10.1016/j.neuroscience.2011.05.016

Hudson, J. W., and Scott, I. M. (1979). Daily Torpor in the Laboratory Mouse, Mus musculus Var. Albino. Physiol. Zool. 52, 205-218. doi: 10.1086/physzool.52.2. 30152564

Ishimori, K. (1909). True cause of sleep: a hypnogenic substance as evidenced in the brain of sleep-deprived animals. Tokyo Igakkai Zasshi 23, 429-457.

Ishiwata, T., Saito, T., Hasegawa, H., Yazawa, T., Kotani, Y., Otokawa, M., et al. (2005). Changes of body temperature and thermoregulatory responses of freely moving rats during GABAergic pharmacological stimulation to the preoptic area and anterior hypothalamus in several ambient temperatures. Brain Res. 1048, 32-40. doi: 10.1016/j.brainres.2005.04.027

Jing, M., Zhang, Y., Wang, H., and Li, Y. (2019). G-protein-coupled receptorbased sensors for imaging neurochemicals with high sensitivity and specificity. J. Neurochem. 151, 279-288. doi: 10.1111/jnc.14855

Kim, C. K., Adhikari, A., and Deisseroth, K. (2017). Integration of optogenetics with complementary methodologies in systems neuroscience. Nat. Rev. Neurosci. 18, 222-235. doi: 10.1038/nrn.2017.15
Knight, Z. A., Tan, K., Birsoy, K., Schmidt, S., Garrison, J. L., Wysocki, R. W., et al. (2012). Molecular profiling of activated neurons by phosphorylated ribosome capture. Cell 151, 1126-1137. doi: 10.1016/j.cell.2012.10.039

Knox, G. V., Campbell, C., and Lomax, P. (1973). Cutaneous temperature and unit activity in the hypothalamic thermoregulatory centers. Exp. Neurol. 40, 717-730. doi: 10.1016/0014-4886(73)90106-4

Kohl, J., and Dulac, C. (2018). Neural control of parental behaviors. Curr. Opin. Neurobiol. 49, 116-122. doi: 10.1016/j.conb.2018.02.002

Koyama, Y., and Hayaishi, O. (1994). Firing of neurons in the preoptic/anterior hypothalamic areas in rat: its possible involvement in slow wave sleep and paradoxical sleep. Neurosci. Res. 19, 31-38. doi: 10.1016/0168-0102(94)90005-1

Kräuchi, K. (2007). The thermophysiological cascade leading to sleep initiation in relation to phase of entrainment. Sleep Med. Rev. 11, 439-451. doi: 10.1016/j. smrv.2007.07.001

Kräuchi, K., Cajochen, C., Werth, E., and Wirz-Justice, A. (1999). Warm feet promote the rapid onset of sleep. Nature 401, 36-37. doi: 10.1038/43366

Krauchi, K., and Deboer, T. (2010). The interrelationship between sleep regulation and thermoregulation. Front. Biosci. 15:604-625. doi: 10.2741/3636

Kroeger, D., Absi, G., Gagliardi, C., Bandaru, S. S., Madara, J. C., Ferrari, L. L., et al. (2018). Galanin neurons in the ventrolateral preoptic area promote sleep and heat loss in mice. Nat. Commun. 9:4129. doi: 10.1038/s41467-018-06590-7

Kumar, S., Rai, S., Hsieh, K.-C., McGinty, D., Alam, M. N., and Szymusiak, R. (2013). Adenosine A2A receptors regulate the activity of sleep regulatory GABAergic neurons in the preoptic hypothalamus. Am. J. Physiol. Regul. Integr. Comp. Physiol. 305, R31-R41. doi: 10.1152/ajpregu.00402.2012

Lack, L. C., Gradisar, M., Van Someren, E. J. W., Wright, H. R., and Lushington, K. (2008). The relationship between insomnia and body temperatures. Sleep Med. Rev. 12, 307-317. doi: 10.1016/j.smrv.2008.02.003

Landolt, H. P., Moser, S., Wieser, H. G., Borbély, A. A., and Dijk, D. J. (1995). Intracranial temperature across 24-hour sleep-wake cycles in humans. Neuroreport 6, 913-917. doi: 10.1097/00001756-199504190-00022

Lavie, P. (2001). Sleep-wake as a biological rhythm. Annu. Rev. Psychol. 52, 277-303. doi: 10.1146/annurev.psych.52.1.277

Legendre, R., and Piéron, H. (1913). Recherches sur le besoin de sommeil consécutif à une veille prolongée. Z. Allg. Physiol. 14, 235-262.

Lipton, J. M. (1968). Effects of preoptic lesions on heat-escape responding and colonic temperature in the rat. Physiol. Behav. 3, 165-169. doi: 10.1016/00319384(68)90049-8

Lu, J., Bjorkum, A. A., Xu, M., Gaus, S. E., Shiromani, P. J., and Saper, C. B. (2002). Selective activation of the extended ventrolateral preoptic nucleus during rapid eye movement sleep. J. Neurosci. 22, 4568-4576. doi: 10.1523/JNEUROSCI.2211-04568.2002

Lu, J., Greco, M. A., Shiromani, P., and Saper, C. B. (2000). Effect of lesions of the ventrolateral preoptic nucleus on NREM and REM sleep. J. Neurosci. 20, 3830-3842.

Lu, J., Zhang, Y.-H., Chou, T. C., Gaus, S. E., Elmquist, J. K., Shiromani, P., et al. (2001). Contrasting effects of ibotenate lesions of the paraventricular nucleus and subparaventricular zone on sleep-wake cycle and temperature regulation. J. Neurosci. 21, 4864-4874. doi: 10.1523/JNEUROSCI.21-13-04864.2001

Luppi, P.-H., Aston-Jones, G., Akaoka, H., Chouvet, G., and Jouvet, M. (1995). Afferent projections to the rat locus coeruleus demonstrated by retrograde and anterograde tracing with cholera-toxin B subunit and Phaseolus vulgaris leucoagglutinin. Neuroscience 65, 119-160. doi: 10.1016/0306-4522(94)00481-J

Ma, Y., Miracca, G., Yu, X., Harding, E. C., Miao, A., Yustos, R., et al. (2019). Galanin neurons unite sleep homeostasis and $\alpha 2$-adrenergic sedation. Curr. Biol. 29, 3315-3322.e3. doi: 10.1016/j.cub.2019.07.087

Machado, N. L. S., Bandaru, S. S., Abbott, S. B. G., and Saper, C. B. (2020). EP3R-expressing glutamatergic preoptic neurons mediate inflammatory fever. J. Neurosci. 40, 2573-2588. doi: 10.1523/JNEUROSCI.2887-19.2020

Magoun, H. W., Harrison, F., Brobeck, J. R., and Ranson, S. W. (1938). Activation of heat loss mechanisms by local heating of the brain. J. Neurophysiol. 1, 101-114. doi: 10.1152/jn.1938.1.2.101

Matsumura, H., Nakajima, T., Osaka, T., Satoh, S., Kawase, K., Kubo, E., et al. (1994). Prostaglandin D2-sensitive, sleep-promoting zone defined in the ventral surface of the rostral basal forebrain. Proc. Natl. Acad. Sci. U.S.A. 91, 1199812002. doi: 10.1073/pnas.91.25.11998

Matsuoka, Y., Furuyashiki, T., Bito, H., Ushikubi, F., Tanaka, Y., Kobayashi, T., et al. (2003). Impaired adrenocorticotropic hormone response to bacterial 
endotoxin in mice deficient in prostaglandin E receptor EP1 and EP3 subtypes. Proc. Natl. Acad. Sci. U.S.A. 100, 4132-4137. doi: 10.1073/pnas.0633341100

McGinty, D., and Szymusiak, R. (1990). Keeping cool: a hypothesis about the mechanisms and functions of slow-wave sleep. Trends Neurosci. 13, 480-487. doi: 10.1016/0166-2236(90)90081-k

McGinty, D., Szymusiak, R., and Thomson, D. (1994). Preoptic/anterior hypothalamic warming increases EEG delta frequency activity within nonrapid eye movement sleep. Brain Res. 667, 273-277. doi: 10.1016/0006-8993(94) 91506-7

McGinty, D. J., and Sterman, M. B. (1968). Sleep suppression after basal forebrain lesions in the cat. Science 160, 1253-1255. doi: 10.1126/science.160.3833.1253

McKinley, M. J., Yao, S. T., Uschakov, A., McAllen, R. M., Rundgren, M., and Martelli, D. (2015). The median preoptic nucleus: front and centre for the regulation of body fluid, sodium, temperature, sleep and cardiovascular homeostasis. Acta Physiol. 214, 8-32. doi: 10.1111/apha.12487

Miracca, G., Soto, B. A., Tossell, K., Yustos, R., Vyssotski, A. L., Franks, N. P., et al. (2020). Hypothalamic NMDA receptors stabilize NREM sleep and are essential for REM sleep. bioRxiv [Preprint]. doi: 10.1101/2020.10.19.345728

Mizoguchi, A., Eguchi, N., Kimura, K., Kiyohara, Y., Qu, W.-M., Huang, Z.-L., et al. (2001). Dominant localization of prostaglandin D receptors on arachnoid trabecular cells in mouse basal forebrain and their involvement in the regulation of non-rapid eye movement sleep. Proc. Natl. Acad. Sci. U.S.A. 98, 11674-11679. doi: 10.1073/pnas.201398898

Moffitt, J. R., Bambah-Mukku, D., Eichhorn, S. W., Vaughn, E., Shekhar, K., Perez, J. D., et al. (2018). Molecular, spatial, and functional single-cell profiling of the hypothalamic preoptic region. Science 362:eaau5324. doi: 10.1126/science. aau5324

Morairty, S. R., Szymusiak, R., Thomson, D., and McGinty, D. J. (1993). Selective increases in non-rapid eye movement sleep following whole body heating in rats. Brain Res. 617, 10-16. doi: 10.1016/0006-8993(93)90606-N

Morrison, S. F. (2003). Raphe pallidus neurons mediate prostaglandin E2-evoked increases in brown adipose tissue thermogenesis. Neuroscience 121, 17-24. doi: 10.1016/s0306-4522(03)00363-4

Morrison, S. F. (2016). Central neural control of thermoregulation and brown adipose tissue. Auton. Neurosci. Basic Clin. 196, 14-24. doi: 10.1016/j.autneu. 2016.02.010

Morrison, S. F., Sved, A. F., and Passerin, A. M. (1999). GABA-mediated inhibition of raphe pallidus neurons regulates sympathetic outflow to brown adipose tissue. Am. J. Physiol. 276, R290-R297. doi: 10.1152/ajpregu.1999.276.2.R290

Nakamura, K. (2011). Central circuitries for body temperature regulation and fever. Am. J. Physiol. Regul. Integr. Comp. Physiol. 301, R1207-R1228. doi: 10.1152/ ajpregu.00109.2011

Nakamura, K., Matsumura, K., Kaneko, T., Kobayashi, S., Katoh, H., and Negishi, M. (2002). The rostral raphe pallidus nucleus mediates pyrogenic transmission from the preoptic area. J. Neurosci. 22, 4600-4610.

Nakayama, T., Eisenman, J. S., and Hardy, J. D. (1961). Single unit activity of anterior hypothalamus during local heating. Science 134, 560-561. doi: 10.1126/ science. 134.3478 .560

Nakayama, T., Hammel, H. T., Hardy, J. D., and Eisenman, J. S. (1963). Thermal stimulation of electrical activity of single units of the preoptic region. Am. J. Physiol. 204, 1122-1126. doi: 10.1152/ajplegacy.1963.204.6.1122

Nauta, W. J. H. (1946). Hypothalamic regulation of sleep in rats. An experimental study. J. Neurophysiol. 9, 285-316. doi: 10.1152/jn.1946.9.4.285

Nitz, D., and Siegel, J. M. (1996). GABA release in posterior hypothalamus across sleep-wake cycle. Am. J. Physiol. Regul. Integr. Comp. Physiol. 271, R1707R1712. doi: 10.1152/ajpregu.1996.271.6.R1707

Nitz, D., and Siegel, J. M. (1997). GABA release in the locus coeruleus as a function of sleep/wake state. Neuroscience 78, 795-801. doi: 10.1016/S0306-4522(96) 00549-0

Obál, F., Rubicsek, G., Alföldi, P., Sáry, G., and Obál, F. (1985). Changes in the brain and core temperatures in relation to the various arousal states in rats in the light and dark periods of the day. Pflugers Arch. 404, 73-79. doi: 10.1007/ BF00581494

Okamoto, K., Yamasaki, M., Takao, K., Soya, S., Iwasaki, M., Sasaki, K., et al. (2016). QRFP-deficient mice are hypophagic, lean, hypoactive and exhibit increased anxiety-like behavior. PLoS One 11:e0164716. doi: 10.1371/journal. pone. 0164716
Ootsuka, Y., de Menezes, R. C., Zaretsky, D. V., Alimoradian, A., Hunt, J., Stefanidis, A., et al. (2009). Brown adipose tissue thermogenesis heats brain and body as part of the brain-coordinated ultradian basic restactivity cycle. Neuroscience 164, 849-861. doi: 10.1016/j.neuroscience.2009. 08.013

Osaka, T. (2004). Cold-induced thermogenesis mediated by GABA in the preoptic area of anesthetized rats. Am. J. Physiol. Regul. Integr. Comp. Physiol. 287, R306-R313. doi: 10.1152/ajpregu.00003.2004

Osaka, T., and Matsumura, H. (1994). Noradrenergic inputs to sleep-related neurons in the preoptic area from the locus coeruleus and the ventrolateral medulla in the rat. Neurosci. Res. 19, 39-50. doi: 10.1016/0168-0102(94)9 0006-X

Osaka, T., and Matsumura, H. (1995). Noradrenaline inhibits preoptic sleep-active neurons through alpha 2-receptors in the rat. Neurosci. Res. 21, 323-330. doi: 10.1016/0168-0102(94)00871-c

Ozaki, S., Uchiyama, M., Shirakawa, S., and Okawa, M. (1996). Prolonged interval from body temperature nadir to sleep offset in patients with delayed sleep phase syndrome. Sleep 19, 36-40.

Pache, M., Kräuchi, K., Cajochen, C., Wirz-Justice, A., Dubler, B., Flammer, J., et al. (2001). Cold feet and prolonged sleep-onset latency in vasospastic syndrome. Lancet 358, 125-126. doi: 10.1016/S0140-6736(01)05344-2

Peever, J. (2018). Neuroscience: a "Skin Warming" circuit that promotes sleep and body cooling. Curr. Biol. 28, R800-R802. doi: 10.1016/j.cub.2018.06.043

Porkka-Heiskanen, T., and Kalinchuk, A. V. (2011). Adenosine, energy metabolism and sleep homeostasis. Sleep Med. Rev. 15, 123-135. doi: 10.1016/j.smrv.2010. 06.005

Porkka-Heiskanen, T., Strecker, R. E., and McCarley, R. W. (2000). Brain site-specificity of extracellular adenosine concentration changes during sleep deprivation and spontaneous sleep: an in vivo microdialysis study. Neuroscience 99, 507-517. doi: 10.1016/s0306-4522(00)00220-7

Porkka-Heiskanen, T., Strecker, R. E., Thakkar, M., Bjørkum, A. A., Greene, R. W., and McCarley, R. W. (1997). Adenosine: a mediator of the sleep-inducing effects of prolonged wakefulness. Science 276, 1265-1268. doi: 10.1126/science.276. 5316.1265

Ray, B., Mallick, H. N., and Kumar, V. M. (2005). Changes in sleep-wakefulness in the medial preoptic area lesioned rats: role of thermal preference. Behav. Brain Res. 158, 43-52. doi: 10.1016/j.bbr.2004.08.006

Raymann, R. J. E. M., and Van Someren, E. J. W. (2008). Diminished capability to recognize the optimal temperature for sleep initiation may contribute to poor sleep in elderly people. Sleep 31, 1301-1309.

Roberts, W. W., and Martin, J. R. (1977). Effects of lesions in central thermosensitive areas on thermoregulatory responses in rat. Physiol. Behav. 19, 503-511. doi: 10.1016/0031-9384(77)90226-8

Roberts, W. W., and Robinson, T. C. (1969). Relaxation and sleep induced by warming of preoptic region and anterior hypothalamus in cats. Exp. Neurol. 25, 282-294. doi: 10.1016/0014-4886(69)90051-x

Sabatini, B. L., and Tian, L. (2020). Imaging neurotransmitter and neuromodulator dynamics in vivo with genetically encoded indicators. Neuron 108, 17-32. doi: 10.1016/j.neuron.2020.09.036

Saito, Y. C., Maejima, T., Nishitani, M., Hasegawa, E., Yanagawa, Y., Mieda, M., et al. (2018). Monoamines inhibit GABAergic neurons in ventrolateral preoptic area that make direct synaptic connections to hypothalamic arousal neurons. J. Neurosci. 38, 6366-6378. doi: 10.1523/JNEUROSCI.2835-17.2018

Saito, Y. C., Tsujino, N., Hasegawa, E., Akashi, K., Abe, M., Mieda, M., et al. (2013). GABAergic neurons in the preoptic area send direct inhibitory projections to orexin neurons. Front. Neural Circuits 7:192. doi: 10.3389/fncir.2013.00192

Sallanon, M., Denoyer, M., Kitahama, K., Aubert, C., Gay, N., and Jouvet, M. (1989). Long-lasting insomnia induced by preoptic neuron lesions and its transient reversal by muscimol injection into the posterior hypothalamus in the cat. Neuroscience 32, 669-683.

Saper, C. B., and Breder, C. D. (1994). The neurologic basis of fever. N. Engl. J. Med. 330, 1880-1886. doi: 10.1056/NEJM199406303302609

Saper, C. B., and Fuller, P. M. (2017). Wake-sleep circuitry: an overview. Curr. Opin. Neurobiol. 44, 186-192. doi: 10.1016/j.conb.2017.03.021

Saper, C. B., Romanovsky, A. A., and Scammell, T. E. (2012). Neural circuitry engaged by prostaglandins during the sickness syndrome. Nat. Neurosci. 15, 1088-1095. doi: 10.1038/nn.3159 
Satinoff, E., and Rutstein, J. (1970). Behavioral thermoregulation in rats with anterior hypothalamic lesions. J. Comp. Physiol. Psychol. 71, 77-82. doi: 10. 1037/h0028959

Satinoff, E., Valentino, D., and Teitelbaum, P. (1976). Thermoregulatory colddefense deficits in rats with preoptic/anterior hypothalamic lesions. Brain Res. Bull. 1, 553-565. doi: 10.1016/0361-9230(76)90082-4

Satoh, S., Matsumura, H., Suzuki, F., and Hayaishi, O. (1996). Promotion of sleep mediated by the A2a-adenosine receptor and possible involvement of this receptor in the sleep induced by prostaglandin D2 in rats. Proc. Natl. Acad. Sci. U.S.A. 93, 5980-5984.

Scammell, T., Gerashchenko, D., Urade, Y., Onoe, H., Saper, C., and Hayaishi, O. (1998). Activation of ventrolateral preoptic neurons by the somnogen prostaglandin D2. Proc. Natl. Acad. Sci. U.S.A. 95, 7754-7759. doi: 10.1073/ pnas.95.13.7754

Scammell, T. E., Arrigoni, E., and Lipton, J. O. (2017). Neural circuitry of wakefulness and sleep. Neuron 93, 747-765. doi: 10.1016/j.neuron.2017.01.014

Scammell, T. E., Elmquist, J. K., Griffin, J. D., and Saper, C. B. (1996). Ventromedial preoptic prostaglandin E2 activates fever-producing autonomic pathways. J. Neurosci. 16, 6246-6254.

Scammell, T. E., Gerashchenko, D. Y., Mochizuki, T., McCarthy, M. T., Estabrooke, I. V., Sears, C. A., et al. (2001). An adenosine A2a agonist increases sleep and induces Fos in ventrolateral preoptic neurons. Neuroscience 107, 653-663.

Scammell, T. E., Price, K. J., and Sagar, S. M. (1993). Hyperthermia induces c-fos expression in the preoptic area. Brain Res. 618, 303-307. doi: 10.1016/00068993(93)91280-6

Schulze, G., Tetzner, M., and Topolinski, H. (1981). Operant thermoregulation of rats with anterior hypothalamic lesions. Naunyn Schmiedebergs Arch. Pharmacol. 318, 43-48. doi: 10.1007/BF00503311

Scott, N., Prigge, M., Yizhar, O., and Kimchi, T. (2015). A sexually dimorphic hypothalamic circuit controls maternal care and oxytocin secretion. Nature 525, 519-522. doi: 10.1038/nature15378

Sela, Y., Hoekstra, M. M., and Franken, P. (2021). Sub-minute prediction of brain temperature based on sleep-wake state in the mouse. eLife 10:e62073. doi: 10.7554/eLife.62073

Sherin, J. E., Elmquist, J. K., Torrealba, F., and Saper, C. B. (1998). Innervation of histaminergic tuberomammillary neurons by GABAergic and galaninergic neurons in the ventrolateral preoptic nucleus of the rat. J. Neurosci. 18, 47054721.

Sherin, J. E., Shiromani, P. J., McCarley, R. W., and Saper, C. B. (1996). Activation of ventrolateral preoptic neurons during sleep. Science 271, 216-219.

Simerly, R. B. (2002). Wired for reproduction: organization and development of sexually dimorphic circuits in the mammalian forebrain. Annu. Rev. Neurosci. 25, 507-536. doi: 10.1146/annurev.neuro.25.112701.142745

Song, K., Wang, H., Kamm, G. B., Pohle, J., Reis, F., de, C., et al. (2016). The TRPM2 channel is a hypothalamic heat sensor that limits fever and can drive hypothermia. Science 353, 1393-1398. doi: 10.1126/science.aaf7537

Spiegel, K., Tasali, E., Leproult, R., and Van Cauter, E. (2009). Effects of poor and short sleep on glucose metabolism and obesity risk. Nat. Rev. Endocrinol. 5, 253-261. doi: 10.1038/nrendo.2009.23

Steininger, T. L., Gong, H., McGinty, D., and Szymusiak, R. (2001). Subregional organization of preoptic area/anterior hypothalamic projections to arousalrelated monoaminergic cell groups. J. Comp. Neurol. 429, 638-653.

Sterman, M. B., and Clemente, C. D. (1962a). Forebrain inhibitory mechanisms: cortical synchronization induced by basal forebrain stimulation. Exp. Neurol. 6, 91-102. doi: 10.1016/0014-4886(62)90080-8

Sterman, M. B., and Clemente, C. D. (1962b). Forebrain inhibitory mechanisms: sleep patterns induced by basal forebrain stimulation in the behaving cat. Exp. Neurol. 6, 103-117. doi: 10.1016/0014-4886(62)90081-x

Szymusiak, R., Alam, N., Steininger, T. L., and McGinty, D. (1998). Sleep-waking discharge patterns of ventrolateral preoptic/anterior hypothalamic neurons in rats. Brain Res. $803,178-188$.

Szymusiak, R., Danowski, J., and McGinty, D. (1991). Exposure to heat restores sleep in cats with preoptic/anterior hypothalamic cell loss. Brain Res. 541, 134-138. doi: 10.1016/0006-8993(91)91086-g

Takahashi, K., Lin, J.-S., and Sakai, K. (2009). Characterization and mapping of sleep-waking specific neurons in the basal forebrain and preoptic hypothalamus in mice. Neuroscience 161, 269-292. doi: 10.1016/j.neuroscience.2009.02.075
Takahashi, T. M., Sunagawa, G. A., Soya, S., Abe, M., Sakurai, K., Ishikawa, K., et al. (2020). A discrete neuronal circuit induces a hibernation-like state in rodents. Nature 583, 109-114. doi: 10.1038/s41586-020-2163-6

Takayasu, S., Sakurai, T., Iwasaki, S., Teranishi, H., Yamanaka, A., Williams, S. C., et al. (2006). A neuropeptide ligand of the G protein-coupled receptor GPR103 regulates feeding, behavioral arousal, and blood pressure in mice. Proc. Natl. Acad. Sci. U.S.A. 103, 7438-7443. doi: 10.1073/pnas.0602371103

Tan, C. L., Cooke, E. K., Leib, D. E., Lin, Y.-C., Daly, G. E., Zimmerman, C. A., et al. (2016). Warm-sensitive neurons that control body temperature. Cell 167, 47-59.e15. doi: 10.1016/j.cell.2016.08.028

Tan, C. L., and Knight, Z. A. (2018). Regulation of body temperature by the nervous system. Neuron 98, 31-48. doi: 10.1016/j.neuron.2018.02.022

Thakkar, M. M., Strecker, R. E., and McCarley, R. W. (1998). Behavioral state control through differential serotonergic inhibition in the mesopontine cholinergic nuclei: a simultaneous unit recording and microdialysis study. J. Neurosci. 18, 5490-5497. doi: 10.1523/JNEUROSCI.18-14-05490.1998

Tsukahara, S., and Morishita, M. (2020). Sexually dimorphic formation of the preoptic area and the bed nucleus of the stria terminalis by neuroestrogens. Front. Neurosci. 14:797. doi: 10.3389/fnins.2020.00797

Tupone, D., Cetas, J. S., and Morrison, S. F. (2016). Hibernation, hypothermia and a possible therapeutic "Shifted Homeostasis" Induced by Central Activation of A1 Adenosine Receptor (A1AR). Nihon Shinkei Seishin Yakurigaku Zasshi 36, 51-54.

Tupone, D., Madden, C. J., and Morrison, S. F. (2013). Central activation of the A1 adenosine receptor (A1AR) induces a hypothermic, torpor-like state in the rat. J. Neurosci. 33, 14512-14525. doi: 10.1523/JNEUROSCI.1980-13.2013

Turek, F. W., Joshu, C., Kohsaka, A., Lin, E., Ivanova, G., McDearmon, E., et al. (2005). Obesity and metabolic syndrome in circadian Clock mutant mice. Science 308, 1043-1045. doi: 10.1126/science.1108750

Urade, Y., Kitahama, K., Ohishi, H., Kaneko, T., Mizuno, N., and Hayaishi, O. (1993). Dominant expression of mRNA for prostaglandin D synthase in leptomeninges, choroid plexus, and oligodendrocytes of the adult rat brain. Proc. Natl. Acad. Sci. U.S.A. 90, 9070-9074. doi: 10.1073/pnas.90.19.9070

Van Zoeren, J., and Stricker, E. (1976). Thermal homeostasis in rats after intrahypothalamic injections of 6-hyroxydopamine. Am. J. Physiol. 230, 932939. doi: 10.1152/ajplegacy.1976.230.4.932

Varin, C., Rancillac, A., Geoffroy, H., Arthaud, S., Fort, P., and Gallopin, T. (2015). Glucose induces slow-wave sleep by exciting the sleep-promoting neurons in the ventrolateral preoptic nucleus: a new link between sleep and metabolism. J. Neurosci. 35, 9900-9911. doi: 10.1523/JNEUROSCI.0609-15.2015

Venner, A., De Luca, R., Sohn, L. T., Bandaru, S. S., Verstegen, A. M. J., Arrigoni, E., et al. (2019). An inhibitory lateral hypothalamic-preoptic circuit mediates rapid arousals from sleep. Curr. Biol. 29, 4155-4168.e5. doi: 10.1016/j.cub.2019. 10.026

von Economo, C. (1930). Sleep as a problem of localization. J. Nerv. Ment. Dis. 71, 249-259.

Watanabe, T., Kajimura, N., Kato, M., Sekimoto, M., Nakajima, T., Hori, T., et al. (2003). Sleep and circadian rhythm disturbances in patients with delayed sleep phase syndrome. Sleep 26, 657-661. doi: 10.1093/sleep/26.6.657

Wever, R. A. (1979). The Circadian System of Man: Results of Experiments Under Temporal Isolation. New York, NY: Springer-Verlag. doi: 10.1007/978-1-46126142-1

Wiegert, J. S., Mahn, M., Prigge, M., Printz, Y., and Yizhar, O. (2017). Silencing neurons: tools, applications, and experimental constraints. Neuron 95, 504-529. doi: 10.1016/j.neuron.2017.06.050

Williams, R. H., Chee, M. J. S., Kroeger, D., Ferrari, L. L., Maratos-Flier, E., Scammell, T. E., et al. (2014). Optogenetic-mediated release of histamine reveals distal and autoregulatory mechanisms for controlling arousal. J. Neurosci. 34, 6023-6029. doi: 10.1523/JNEUROSCI.4838-13.2014

Wit, A., and Wang, S. C. (1968). Temperature-sensitive neurons in preopticanterior hypothalamic region: effects of increasing ambient temperature. Am. J. Physiol. 215, 1151-1159. doi: 10.1152/ajplegacy.1968.215.5.1151

Xu, M., Chung, S., Zhang, S., Zhong, P., Ma, C., Chang, W.-C., et al. (2015). Basal forebrain circuit for sleep-wake control. Nat. Neurosci. 18, 1641-1647. doi: 10.1038/nn.4143

Yamaguchi, H., Hopf, F. W., Li, S.-B., and de Lecea, L. (2018). In vivo cell type-specific CRISPR knockdown of dopamine beta hydroxylase reduces locus 
coeruleus evoked wakefulness. Nat. Commun. 9:5211. doi: 10.1038/s41467-01807566-3

Yoshida, K., Konishi, M., Nagashima, K., Saper, C. B., and Kanosue, K. (2005). Fos activation in hypothalamic neurons during cold or warm exposure: projections to periaqueductal gray matter. Neuroscience 133, 1039-1046. doi: 10.1016/j. neuroscience.2005.03.044

Yoshida, K., Li, X., Cano, G., Lazarus, M., and Saper, C. B. (2009). Parallel preoptic pathways for thermoregulation. J. Neurosci. 29, 11954-11964. doi: 10.1523/ JNEUROSCI.2643-09.2009

Yu, S., François, M., Huesing, C., and Münzberg, H. (2018). The hypothalamic preoptic area and body weight control. Neuroendocrinology 106, 187-194. doi: $10.1159 / 000479875$

Yu, S., Qualls-Creekmore, E., Rezai-Zadeh, K., Jiang, Y., Berthoud, H.-R., Morrison, C. D., et al. (2016). Glutamatergic preoptic area neurons that express leptin receptors drive temperature-dependent body weight homeostasis. J. Neurosci. 36, 5034-5046. doi: 10.1523/JNEUROSCI.0213-16.2016

Zhang, Y., Kerman, I. A., Laque, A., Nguyen, P., Faouzi, M., Louis, G. W., et al. (2011). Leptin-receptor-expressing neurons in the dorsomedial hypothalamus and median preoptic area regulate sympathetic brown adipose tissue circuits. J. Neurosci. 31, 1873-1884. doi: 10.1523/JNEUROSCI.322310.2011

Zhang, Z., Ferretti, V., Güntan, İ., Moro, A., Steinberg, E. A., Ye, Z., et al. (2015). Neuronal ensembles sufficient for recovery sleep and the sedative actions of $\alpha 2$ adrenergic agonists. Nat. Neurosci. 18, 553-561. doi: 10.1038/nn. 3957

Conflict of Interest: The authors declare that the research was conducted in the absence of any commercial or financial relationships that could be construed as a potential conflict of interest.

Copyright (ङ 2021 Rothhaas and Chung. This is an open-access article distributed under the terms of the Creative Commons Attribution License (CC BY). The use, distribution or reproduction in other forums is permitted, provided the original author(s) and the copyright owner(s) are credited and that the original publication in this journal is cited, in accordance with accepted academic practice. No use, distribution or reproduction is permitted which does not comply with these terms. 